\title{
Transcriptomic profiling of TK2 deficient human skeletal muscle suggests a role for the p53 signalling pathway and identifies growth and differentiation factor-15 as a potential novel biomarker for mitochondrial myopathies
}

Susana Graciela Kalko', Sonia Paco ${ }^{2}$, Cristina Jou 2,3, Maria Angels Rodríguez², Marija Meznaric ${ }^{4}$, Mihael Rogac ${ }^{5}$, Maja Jekovec-Vrhovsek ${ }^{5}$, Monica Sciacco ${ }^{6}$, Maurizio Moggio ${ }^{6}$, Gigliola Fagiolari ${ }^{6}$, Boel De Paepe ${ }^{7}$, Linda De Meirleir ${ }^{7}$, Isidre Ferrer ${ }^{8}$, Manel Roig-Quilis ${ }^{9}$, Francina Munell ${ }^{9}$, Julio Montoya ${ }^{10,11}$, Ester López-Gallardo ${ }^{10,11}$, Eduardo Ruiz-Pesini ${ }^{10,11}$, Rafael Artuch ${ }^{11,12}$, Raquel Montero ${ }^{11,12}$, Ferran Torner ${ }^{13}$, Andres Nascimento ${ }^{2,11}$, Carlos Ortez ${ }^{2}$, Jaume Colomer ${ }^{2,11}$ and Cecilia Jimenez-Mallebrera ${ }^{2,11^{*}}$

\begin{abstract}
Background: Mutations in the gene encoding thymidine kinase 2 (TK2) result in the myopathic form of mitochondrial DNA depletion syndrome which is a mitochondrial encephalomyopathy presenting in children. In order to unveil some of the mechanisms involved in this pathology and to identify potential biomarkers and therapeutic targets we have investigated the gene expression profile of human skeletal muscle deficient for TK2 using CDNA microarrays.

Results: We have analysed the whole transcriptome of skeletal muscle from patients with TK2 mutations and compared it to normal muscle and to muscle from patients with other mitochondrial myopathies. We have identified a set of over 700 genes which are differentially expressed in TK2 deficient muscle. Bioinformatics analysis reveals important changes in muscle metabolism, in particular, in glucose and glycogen utilisation, and activation of the starvation response which affects aminoacid and lipid metabolism. We have identified those transcriptional regulators which are likely to be responsible for the observed changes in gene expression.

Conclusion: Our data point towards the tumor suppressor p53 as the regulator at the centre of a network of genes which are responsible for a coordinated response to TK2 mutations which involves inflammation, activation of muscle cell death by apoptosis and induction of growth and differentiation factor 15 (GDF-15) in muscle and serum. We propose that GDF-15 may represent a potential novel biomarker for mitochondrial dysfunction although further studies are required.
\end{abstract}

Keywords: Gene expression, Microarrays, Bioinformatics, Mitochondrial DNA, Mitochondrial DNA depletion, Mitochondrial encephalomyopathy, Thymidine kinase 2, Skeletal muscle, p53, Apoptosis, GDF-15

\footnotetext{
* Correspondence: cjimenezm@hsjdbcn.org

${ }^{2}$ Neuromuscular Unit, Neurology Department, Fundación Sant Joan de Déu,

Hospital Sant Joan de Déu, Barcelona, Spain

${ }^{11}$ Center for Biomedical Research on Rare Diseases (CIBERER), Instituto de

Salud Carlos III, Madrid, Spain

Full list of author information is available at the end of the article
} 


\section{Background}

Mitochondrial myopathy and mitochondrial encephalomyopathy are terms that define a group of neurological disorders characterized by defective oxidative phosphorylation [1-3]. Multiple organs may be affected including skeletal muscle, liver and central nervous system. The genetics and pathogenesis of mitochondrial disorders are complex because of the interaction of the mtDNA and nuclear genomes. The mtDNA contains 37 genes encoding 13 mitochondrial proteins. The remaining of the over 1500 predicted mitochondrial proteins are encoded by the nuclear genome [4]. The majority of these nuclear genes are unknown (over 50 are known as disease causative genesmaking it very difficult to diagnose at the molecular level mitochondrial disorders not due to mtDNA mutations $[5,6]$.

Mitochondrial DNA depletion syndrome (MDS) is a clinically and genetically heterogeneous subgroup of mitochondrial diseases of nuclear origin which is characterised by severe reduction of mtDNA content in specific tissues, mainly muscle, liver and brain To date 9 nuclear genes have been identified as causing MDS which encode proteins directly involved in the maintenance of the mitochondrial deoxyribonucleoside triphosphate pools (dNTPs) such as Thymidine kinase 2 (TK2), deoxyguanosine kinase (DGOUK), p53 dependent ribonucleotide reductase subunit 2 (RRM2B) and thymidine phosphorylase (TYMP), or in mtDNA replication such as mtDNA polymerase $\gamma$ (POLG) and Twinkle (C10orf2). The role of the other three MDS causative gene products (MPV17), and the $\alpha$ and $\beta$ subunits of succinate-CoA ligase (SUCLG1 and SUCLA2 respectively) in mtDNA maintenance is less clear [7].

Clinically, MDS are divided into myopathic, hepatocerebellar or encephalomyopathic, depending on which tissues are mainly affected at the onset of the symptoms. The myopathic form is most frequently associated with mutations in the TK2, SUCLA2 and RRM $2 B$ genes. Thymidine kinase 2 is responsible for the phosphorylation of pyrimidine nucleosides (deoxythymidine, deoxycytosine and deoxyuridine) inside the mitochondria as part of the salvage pathway. In contrast, thymidine kinase 1 (TK1) participates in the de novo deoxythymidine monophosphate (dTMP) synthesis pathway in the cytoplasm which is then imported into mitochondria. In most reported cases mutations in TK2 result in almost complete absence of enzyme activity and as a consequence in a very severe reduction in mtDNA content $(>90 \%)$ which leads to combined respiratory chain complexes deficiency. Myopathic MDS due to TK2 defects is characterised by neonatal or early onset of hypotonia which progresses rapidly into a severe myopathy and infantile death because of respiratory failure although there are reports of patients which survive longer $[8,9]$. Electromyography shows myopathic signs; creatine kinase levels $(\mathrm{CK})$ are markedly elevated and lactate is moderately high. In addition to muscle symptoms patients may also have CNS involvement [7,10-12]. At the pathological level, muscle biopsies frequently show dystrophic changes with loss of muscle fibres, proliferation of connective and adipose tissues, ragged red fibers with mitochondria proliferation and profound cytochrome c oxidase deficiency and increased intracellular lipid content [10]. To date, more than 20 missense mutations, deletions and insertions have been reported in the TK2 gene. Some of them have been reported in more than one non-related families [11,12].

Two mouse models of TK2 defects have been generated. Tk2 knocked-out mice [13,14] suffer growth retardation and hypothermia and die within 2-4 weeks of life. They show progressive depletion of mtDNA in skeletal muscle, heart and liver. The morphology of skeletal muscle seems unaffected whereas cardiac muscle is disorganised and contains abnormally structured mitochondria. The authors conclude that Tk2 is necessary for deoxythymidine triphosphate (dTTP) synthesis in nonreplicating cells, whereas fast-replicating cells rely more heavily on the de novo synthesis pathway. Thus, as tissues mature, mtDNA replication is increasingly affected and mtDNA depletion worsens. Detailed analysis of the neurological features of these mice revealed an ataxic phenotype with progressive loss of mtDNA content, respiratory chain activity and protein content of mitochondrially encoded respiratory chain subunits in brain tissue, which is accompanied by selective loss of neuronal types [13]. The Tk2 knock-in mice bear the human H126N missense mutation and also showed growth retardation and had a generalized weakness, tremor and impaired gait [15]. Tk2 activity was severely reduced in all tissues tested (3\% and $1.7 \%$ of normal in skeletal muscle and brain respectively) confirming that the mutation severely disrupts Tk2 function. Brain and spinal cord showed the most prominent mtDNA depletion followed by skeletal muscle, heart and kidney whereas in contrast to the $\mathrm{KO}$ model, liver mtDNA content was normal. Activities of the respiratory chain enzymes were selectively reduced in brain and spinal cord whereas they were normal in skeletal muscle. Histological analysis of skeletal muscle was unremarkable. In contrast, the equivalent homozygous mutation in humans resulted in severe myopathy [16]. Thus, neither of the two mouse models replicates the severe muscle phenotype and pathology seen in humans.

How the muscle cell responds to mtDNA depletion, impaired oxidative phosphorylation and severe loss of energy production and how these mechanisms differ between MDS and other mitochondrial myopathies is not well understood. A patient was described which survived into adulthood. Analysis of his two consecutive muscle biopsies revealed an increase in mtDNA content with 
time which paradoxically was accompanied by a decrease in complex IV activity and severe muscle mass and fibre loss $[8,17]$. These findings suggest that there may have been a selective loss of the most affected fibres and that a compensatory mechanism may be acting in these patients to maintain mtDNA levels in surviving muscle fibres. Identification of such compensatory pathways would be of great importance to devise potential therapies.

In order to address some of these questions we undertook global gene expression analysis of muscle biopsies from MDS patients with mutations in TK2 and compared it with that of patients with mtDNA large deletions and aged matched normal muscle. We found a large number of genes whose expression was significantly changed which represent the molecular signature of TK2 deficient human muscle. Our data show that the activation of p53 signalling pathway is relevant to the pathogenesis of TK2 defects and show that energy production via glucose and glycogen metabolism are significantly impaired at the transcriptional level. In contrast, genes known to be part of the starvation response mechanism were increased. We describe the over-expression of growth and differentiation factor 15 (GDF-15) in muscle and serum and its potential use as a novel biomarker of mitochondrial disease.

\section{Results}

\section{Patients and microarray}

In the cDNA microarray we included 4 unrelated patients with MDS and mutations in TK2 (patients 1, 2, 3 and 4 , MDS group), 4 patients with large mtDNA deletions as disease control group (patients 5, 6, 7 and 8, MDEL group) and 4 aged-matched healthy individuals (normal control group) (Table 1). Whole genome was analysed using Agilent Human $8 \times 60 \mathrm{~K}$ arrays. Standard array quality controls were performed showing satisfactory results. Unsupervised bi-clustering analysis considering the Agilent oligonucleotides with the largest variations across the whole experiment showed an appropriate segregation of the different samples. Data has been deposited at the National Centre for Biotechnology Information Gene Expression Omnibus (GEO) database as GEO Series accession number GSE43698.

\section{Genes differentially expressed in mtDNA depleted muscle versus control muscle \\ Summary}

Using the statistical test RankProd we identified 336 unique genes that were significantly under-expressed and 437 that were significantly over-expressed at FDR $<0.05$ in MDS muscle compared to control muscle (Table 2). The list of differentially expressed unique genes is shown in Additional file 1 . The 10 top under-expressed and overexpressed genes in this comparison are listed in Table 3.
The fold changes are remarkable, particularly for the induced genes (up to 188 fold increase) whereas they are more moderate for the repressed genes (maximum 10 fold decrease).

Amongst the top under-expressed genes we found some genes encoding skeletal muscle components characteristic of type II muscle fibres (fast) such as sarcoplasmic reticulum $\mathrm{Ca}^{2+}$ ATPase 1 (ATP2A1), myosinlight chain kinase 2 (MYLK2), actinin-type 3 (ACTN3) and aquaporin-4 (AQP4). These changes indicate a selective loss of type II fibres. In fact, type 1 predominance has been reported in some of the patients included in our microarray [11,12].

Fructose-1,6-bisphosphatase 2 (FBP2) is the gene encoding the muscle specific enzyme responsible for the hydrolysis of fructose-1, 6-bisphosphatase into fructose 6-phosphate and inorganic phosphate during gluconeogenesis. As we will see later we found several other genes involved in glucose and glycogen metabolism amongst the significantly under-expressed genes including glycogen phosphorylase (PYGM).

Ankyrin repeat domain-containing protein 23 is a member of the muscle ankyrin repeat protein family (MARP). The protein is localized to the nucleus, functioning as a transcriptional regulator. Expression of this protein is induced during recovery following starvation [18].

Glutamate-ammonia ligase (or gluthamine synthethase, GLUL) is responsible for the synthesis of glutamine. GLUL is expressed throughout the body and plays an important role in controlling body $\mathrm{pH}$ and removing ammonia from the circulation [19].

The ARRDC2 protein belongs to a family of proteins some of which are involved in ubiquitination by the E3 NEDD4 ligase [20,21]. TRIM63 encodes for the muscle specific E3 ubiquitin ligase MURF1 which is involved in regulating skeletal muscle fibre atrophy. We and others have found decreased TRIM63 RNA expression in chronic atrophy and in diseased muscle [21].

Regarding the top over-expressed genes, growth and differentiation factor 15 (GDF-15) encodes a cytokine which has been involved in a variety of processes including reduced risk of miscarriage and myocardial infarction [22]. Tribbles-homolog 3 (TRIB3) is a pseudokinase which negatively regulates $N F-\kappa B$ signalling and sensitizes cells to TNF and TRAIL induced apoptosis. In addition, expression of TRIB3 increases during periods of reduced nutrient supply to induce lipolysis [23].

MYH3, MYH8 and TNNT2 encode for the neonatal, embryonic myosin heavy chain and cardiac troponin 2 respectively and are markers of muscle fibre regeneration.

COL19A1 encodes for the alpha-1 chain of collagen XIX which we have found similarly over-expressed in various dystrophies including Duchenne muscular dystrophy (unpublished observation) and probably reflects 
Table 1 Clinical summary of patients (* indicates those patients included in the microarray analysis)

\begin{tabular}{|c|c|c|c|c|c|c|c|}
\hline Patient & Onset & Main clinical symptoms & $\begin{array}{l}\text { Age at } \\
\text { biopsy }\end{array}$ & Genetics & $\begin{array}{l}\text { Respiratory chain } \\
\text { enzymes activities }\end{array}$ & $\begin{array}{l}\text { Muscle } \\
\text { pathology }\end{array}$ & References \\
\hline *P1 & $2 y$ & $\begin{array}{l}\text { Hypotonia, weakness, progressive gait } \\
\text { impairment. Unable to stand. CK } 2200 \mathrm{U} / \mathrm{L}\end{array}$ & $2 y$ & $\begin{array}{l}\text { 96\% mtDNA } \\
\text { depletion Hom } \\
\text { A181V TK2 }\end{array}$ & N/A & $\begin{array}{l}\text { Dystrophic, severe } \\
\text { COX reduction. No } \\
\text { RRF. Type } 1 \\
\text { predominance }\end{array}$ & $\begin{array}{l}\text { Family } 1 \text { P2 } \\
\text { Galbiati et al., } \\
2006[12]\end{array}$ \\
\hline *P2 & $3 y$ & $\begin{array}{l}\text { Hypotonia, weakness, walking difficulties, } \\
\text { exercise intolerance, ptosis, } \\
\text { ophthalmoplegia, cerebellar vermis } \\
\text { atrophy. CK } 523 \mathrm{U} / \mathrm{L}\end{array}$ & $4 y$ & $\begin{array}{l}\text { 92\% mtDNA } \\
\text { depletion het } \\
\text { C108W + L257P TK2 }\end{array}$ & $\begin{array}{l}\text { Complex I, III and } \\
\text { IV deficiency }\end{array}$ & $\begin{array}{l}\text { Dystrophic, COX } \\
\text { negative fibres } \\
\text { (74\%). RRF (68\%). } \\
\text { Moderate increase } \\
\text { intracellular lipid. } \\
\text { Type } 1 \\
\text { predominance }\end{array}$ & $\begin{array}{l}\text { Family } 2 \text { P2 } \\
\text { Galbiati et al., } \\
2006[12]\end{array}$ \\
\hline *P3 & $2 y$ & $\begin{array}{l}\text { Unstable gait, muscle hypotrophy. } \\
\text { CK } 800 \text { U/L }\end{array}$ & $2 y$ & $\begin{array}{l}90 \% \text { mtDNA } \\
\text { depletion, Hom } \\
\text { A181V TK2 }\end{array}$ & $\begin{array}{l}\text { Complex I, III, IV } \\
\text { and V deficiency }\end{array}$ & $\begin{array}{l}\text { Dystrophic, COX } \\
\text { negative fibres. } \\
\text { Increased } \\
\text { intracellular lipids }\end{array}$ & $\begin{array}{l}\text { Pat E Spinazzola } \\
\text { et al., } 2009 \text { [1 1] }\end{array}$ \\
\hline *P4 & $2 y$ & $\begin{array}{l}\text { Unstable gait, muscle hypotrophy. } \\
\text { CK } 1000 \mathrm{U} / \mathrm{L}\end{array}$ & $2 y$ & $\begin{array}{l}\text { 90\% mtDNA } \\
\text { depletion, Hom } \\
\text { A181V TK2 }\end{array}$ & $\begin{array}{l}\text { Complex I, III, IV } \\
\text { and V deficiency }\end{array}$ & $\begin{array}{l}\text { Dystrophic, COX } \\
\text { negative fibres. } \\
\text { Increased } \\
\text { intracellular lipids }\end{array}$ & $\begin{array}{l}\text { Pat C Spinazzola } \\
\text { et al. } 2009[11]\end{array}$ \\
\hline *P5 & $5 y$ & $\begin{array}{l}\text { Low stature, lactic acidosis } \\
\text { hypothyroidism, retinitis pigmentosa. }\end{array}$ & $6 y$ & $\begin{array}{l}\text { 6331-13994 (7.7 kb) } \\
64 \% \text { mtDNA }\end{array}$ & Normal & RRF & \\
\hline *P6 & $7 y$ & $\begin{array}{l}\text { Retinitis pigmentosa } \\
\text { leukoenchephalopathy deafness }\end{array}$ & $9 y$ & $11033-1515770 \%$ & $\mathrm{Cl}-\mathrm{CIII} / \mathrm{CII}$ & RRF & $\begin{array}{l}\text { Pineda et al., } \\
2006\end{array}$ \\
\hline *P7 & $30 y$ & $\begin{array}{l}\text { Retinitis pigmentosa deafness, ataxia, } \\
\text { myopathy, heart conduction defects. }\end{array}$ & $30 y$ & $\begin{array}{l}\text { 6331-13994 77\% } \\
\text { mtDNA molecules }\end{array}$ & Normal & RRF & \\
\hline *P8 & $15 y$ & $\begin{array}{l}\text { PEO, pigmentary degeneration of retina, } \\
\text { complete AV block and myopathy }\end{array}$ & 31 y & $\begin{array}{l}8.4 \mathrm{kDa} \text { deletion; } \\
35 \% \text { mtDNA } \\
\text { molecules }\end{array}$ & N/A & $\begin{array}{l}\text { COX negative } \\
\text { fibres and RRF. }\end{array}$ & \\
\hline P9 & $30 y$ & Eyelid ptosis & 38 y & $\begin{array}{l}4.8 \mathrm{kDa} \text { mtDNA } \\
\text { deletion; } 40 \% \\
\text { molecules }\end{array}$ & N/A & $\begin{array}{l}\text { COX negative } \\
\text { fibres and RRF. }\end{array}$ & \\
\hline P10 & $4 \mathrm{~m}$ & $\begin{array}{l}\text { Delayed motor milestones, hypotonia, } \\
\text { dystonia, severe axial muscle weakness, } \\
\text { brisk deep tendon reflex and mild } \\
\text { spasticity in lower limbs. Neurosensorial } \\
\text { deafness. Mild methyl malonic aciduria }\end{array}$ & $7 \mathrm{~m}$ & $\begin{array}{l}\text { 87\% mtDNA } \\
\text { depletion het. p. } \\
\text { G350S + p.G350V } \\
\text { SUCLA } 2\end{array}$ & $\begin{array}{l}\text { Complex II, III and } \\
\text { IV deficiency }\end{array}$ & $\begin{array}{l}\text { Generalized COX } \\
\text { reduction. No RRF. } \\
\text { Moderate increase } \\
\text { intracellular lipids }\end{array}$ & \\
\hline P11 & $1.5 \mathrm{y}$ & $\begin{array}{l}\text { Proximal muscle weakness, mildly } \\
\text { elevated CK levels. }\end{array}$ & $\begin{array}{c}4 \text { and } \\
5 y\end{array}$ & $\begin{array}{l}\text { 95\% mtDNA } \\
\text { depletion het. p. } \\
\text { T77M + p. R161K } \\
\text { TK2 }\end{array}$ & Normal & $\begin{array}{l}\text { COX negative } \\
\text { fibres. Type } 1 \\
\text { predominance }\end{array}$ & $\begin{array}{l}\text { Wang et al., } \\
\text { 2005; Vilá et al., } \\
2008 \text { [8] and } \\
2010\end{array}$ \\
\hline P12 & $10 \mathrm{yrs}$ & $\begin{array}{l}\text { Exercise intolerance, myalgia, lactic } \\
\text { acidosis, eyelid ptosis, CK } 400 \mathrm{U} / \mathrm{L}, \\
\text { hypertrophic cardiomyopathy, epilepsy }\end{array}$ & $13 y$ & $\begin{array}{l}\text { A3243G tRNA-LEU } \\
\text { mtDNA }\end{array}$ & N/A & RRF & \\
\hline
\end{tabular}

Yrs: years; mtDNA: mitochondrial DNA; COX: cytochrome oxidase; RRF: Ragged-red-fibres; CK: serum creatine kinase; PEO: progressive external ophthalmoplegia; CK: creatine kinase; $y$ : years; $m$ : months.

Table 2 Summary of differential genes in MDS vs control muscle

\begin{tabular}{lll}
\hline MDS vs Control & DOWN & UP \\
\hline FDR $<0.05$ & 336 & 437 \\
FDR $<0.05 \&$ IPA SKM & 268 & 279
\end{tabular}

Number of unique genes. MDS: mitochondrial DNA depletion syndrome group. FDR: False Discovery Rate. IPA SKM: genes filtered by expression in skeletal muscle according to Ingenuity Pathway Analysis database. the amount of fibrosis observed in the muscle biopsies of these patients $[11,12]$.

\section{Skeletal muscle expression}

To ascertain which differentially expressed genes are known to be expressed in skeletal muscle we filtered the gene dataset $($ FDR $<0.05)$ using Ingenuity Pathways (IPA)knowledge base (which is based on GNF body atlas and literature findings). Among the 336 under-expressed genes, 268 passed this filter and 279 among the 437 overexpressed genes (Table 2). Using this filter we lost 2 
Table 3 Top Ten under-expressed and over-expressed genes in MDS vs control muscle

\begin{tabular}{llll}
\hline Gene name & Description & FC & FDR \\
\hline Under-expressed & & & \\
ATP2A1 & ATPase, Ca++ transporting, cardiac & -9.1 & 0 \\
& muscle, fast twitch 1 & & \\
FBP2 & Fructose-1,6-bisphosphatase 2 & -9.1 & 0 \\
MYLK2 & Myosin light chain kinase 2 & -7.1 & 0 \\
ANKRD23 & Ankyrin- repeat domain containing & -7.1 & 0 \\
& protein 23 & & \\
ACTN3 & Actinin, alpha 3 & -6.9 & 0 \\
AQP4 & Aquaporin 4 & -6.2 & $5.88 \mathrm{E}-04$ \\
GLUL & Glutamine synthase & -5.9 & 0.002 \\
SMTNL2 & Smoothelin-like 2 & -6.2 & $2.86 \mathrm{E}-04$ \\
ARRDC2 & Arrestin domain containing 2 & -5.8 & $2.86 \mathrm{E}-04$ \\
TRIM63 & Tripartite motif containing 63, E3 & -5.5 & 0.002 \\
& ubiquitin protein ligase & -4.8 & 0.001
\end{tabular}

\section{Over-expressed}

$\begin{array}{llll}\text { GDF15 } & \text { Growth Differentiation Factor 15 } & 188 & 0 \\ \text { MYH8 } & \text { Myosin Heavy Chain Embryonic } & 119 & 0 \\ \text { TRIB3 } & \text { Tribbles homolog 3 } & 47 & 0 \\ \text { MYH3 } & \text { Myosin Heavy Chain Neonatal } & 24 & 0 \\ \text { SNAR-A3 } & \text { Small nuclear ILF3/NF90-associated } & 23 & 0 \\ & \text { RNA A3 } & 21 & 0 \\ \text { TNNT2 } & \text { Troponin T2, cardiac } & 16 & 0 \\ \text { DEFB1 } & \text { Defensin beta-1 malignant brain } & & \\ & \text { tumours 1 } & 16 & 0 \\ \text { TMEM63C } & \text { Transmembrane protein 63C } & 11.3 & 0 \\ \text { DMBT1 } & \text { Deleted in malignant brain tumors } 1 & 11 & 0 \\ \text { COL19A1 } & \text { Collagen type XIX } & 11 & \end{array}$

MDS: mitochondrial DNA depletion syndrome group. FC: fold-change; FDR: false discovery rate.

genes in the top 10 over-expressed genes (SNAR-A3, TMEM63C). All the top 10 under-expressed genes in the whole set of genes passed the IPA filter. Thus, there was very good agreement between the results of the analysis for the whole set of genes and for the skeletal muscle filtered one. However, IPA may discard some genes with low basal expression levels in skeletal muscle, genes that are tightly developmentally regulated or have not been described as expressed in skeletal muscle. For this reason we decided to focus on the whole set of genes in order to avoid loosing valuable data.

\section{Gene ontology}

In order to obtain Gene Ontology enrichment analysis, the lists of differentially over and underexpressed genes $(\mathrm{FDR}<0.05)$ were considered in the tool DAVID [24]. Those GO_BP terms (Gene Ontology Biological Process) with $\mathrm{a} \% \mathrm{FDR}<20$ were considered as significantly enriched and selected for further analysis (49GO_BPs for the overexpressed genes and 91 for the under-expressed genes, Additional file 2). For simplicity, we grouped the various GO terms in broader GO_BP categories as shown in Figure 1 (Additional file 2). The GO_BP classes corresponding to the under-expressed genes (Figure 1A) were mainly related to carbohydrate metabolism, respiratory chain and oxidative phosphorylation, nucleotide metabolism and muscle contraction whereas over-expressed genes were mainly associated with inflammation, apoptosis, aminoacid and nitrogen compound metabolism, organic acid synthesis, adhesion, ion homeostasis, muscle system and oxygen transport (Figure 1B).

The inflammation gene class included components of the complement cascade such as $C 3(\mathrm{FC}+2.5)$, Major Histocompatibility Complex Class I such as HLA-B (FC+ 2.53), major Histocompatibility Complex Class II such as HLA-DPA1 $(\mathrm{FC}+1.7 \times)$, interleukins $(I L 17 B, \mathrm{FC}+2.4)$ and interferon-induced genes (IFI44, FC+3.2 and IFI44L, FC + 3.7). We confirmed the induction of an immune response by immunohistochemistry using antibodies against HLA antigen (MHC-Class I) and against inflammatory cell markers in muscle biopsies from patients with TK2 mutations ( $\mathrm{P} 4$ and in two consecutive biopsies from an additional patient not included in the array, P11 Table 1), a patient with MDS due to SUCLA2 mutations (P10, Table 1) and in disease controls (P5, P6 and P7 with large mtDNA deletions, Table 1). In TK2 deficient muscle HLA I was expressed in the sarcolemma and/or cytoplasm of some muscle fibres and in inflammatory cells. HLA I was detected on the sarcolemma of most fibres and in inflammatory cells in SUCLA2 deficient muscle. In muscle from patients with large mtDNA deletions, HLA I was expressed on isolated muscle fibres located near ragged red fibres (Figure 2). In all cases, the inflammatory infiltrate was mainly composed of macrophages which express CD68 (data not shown).

Within the enriched ontologies related to the regulation of cell death by apoptosis and the cell cycle we found numerous genes that were induced at comparable levels suggesting their coordinated regulation. They include genes that encode molecules that transmit apoptotic signals from the cell surface $(B I D,+$ FC 3.2) and others that are activated via intracellular signals such as DNA damage via the p53 pathway (osteopontin/SPP1, FC + 3.4; PUMA FC + 3.4) and genes that encode key regulators of the cell cycle such as p21 or cyclin dependent kinase inhibitor 1 $(C D K N 1 A, F C+3.7)$ and growth arrest and DNA-damageinducible alpha (GADD45A FC + 2.2).

One of the most over-expressed genes in TK2 deficient muscle corresponds to TRIB3 $(\mathrm{FC}+47)$ which encodes a putative kinase which is induced by $\mathrm{NF}_{\kappa} \mathrm{B}$ and which in turn inhibits the activity of the latter. TRIB3 sensitizes cells to apoptosis induced by TRAIL and TNF and it has 

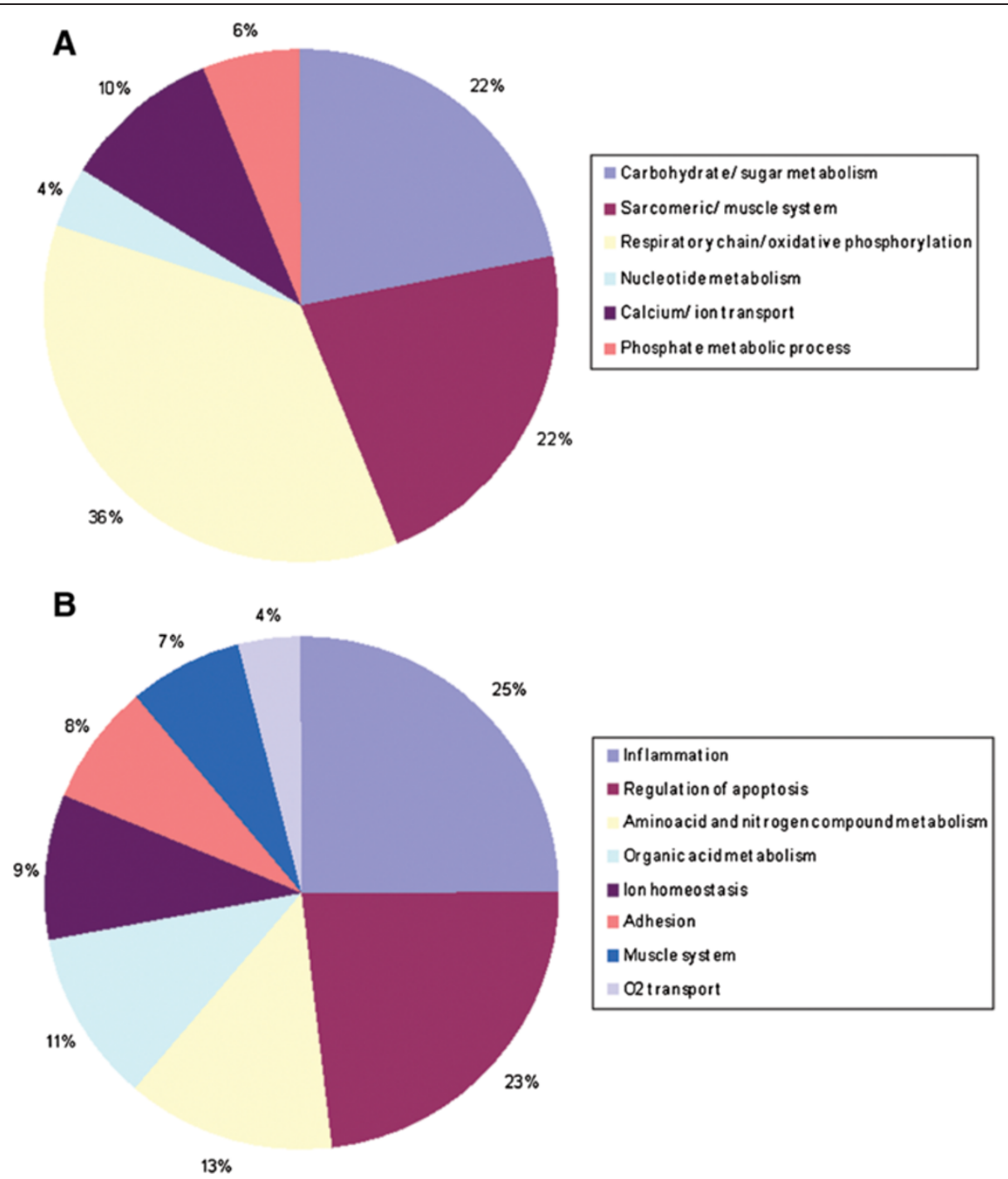

Figure 1 Pie charts representing GO BP categories for (A) under-expressed and (B) over-expressed genes in MDS compared to control muscle.

been shown to interact with Akt1 inhibiting its prosurvival effect.

Several of the apoptotic signals above mentioned converge in the mitochondria and lead to the release of cytochrome $c$ and the activation of Apaf- 1 and Caspase-3. We investigated caspase- 3 activation at the protein level by immunofluorescence in the muscle biopsies of 3 patients with TK2 mutations (P3, P4 and P11) and other mitochondrial encephalomyopathies (P7 and P12, Table 1). As a positive control we stained frozen sections from Wilms Tumor, which is a form of paediatric nephroblastoma which shows high numbers of apoptotic cells. We observed very strong immunoreactivity against active caspase- 3 in the cytoplasm of numerous fibres in TK2 deficient muscle as well as in RRF in P7 and P12 (Figure 3).
Caspase-3 activation leads to DNA fragmentation so we performed the TUNEL assay in muscle biopsies from patients with TK2 mutations (P3, P4), a patient with SUCLA2 mutations (P10, Table 1) and patients with confirmed mitochondrial encephalomyopathy (P6, P7 and P12). We observed TUNEL positivity in myonuclei and apoptotic bodies in TK2 deficient muscle as well as in some of the myonuclei of the RRF in a patient with a MELAS phenotype (P12) (Figure 4).

Several genes encoding enzymes involved in aminoacid, urea cycle and lipid metabolism were overexpressed in response to TK2 deficiency. Noteworthy is the induction of SHMT2 $(\mathrm{FC}+3.4)$ encoding serine hydroxymethyltransferase- 2 that catalyses the conversion of serine and tetrahydrofolate (THF) to glycine and methylene THF. More importantly in the context 


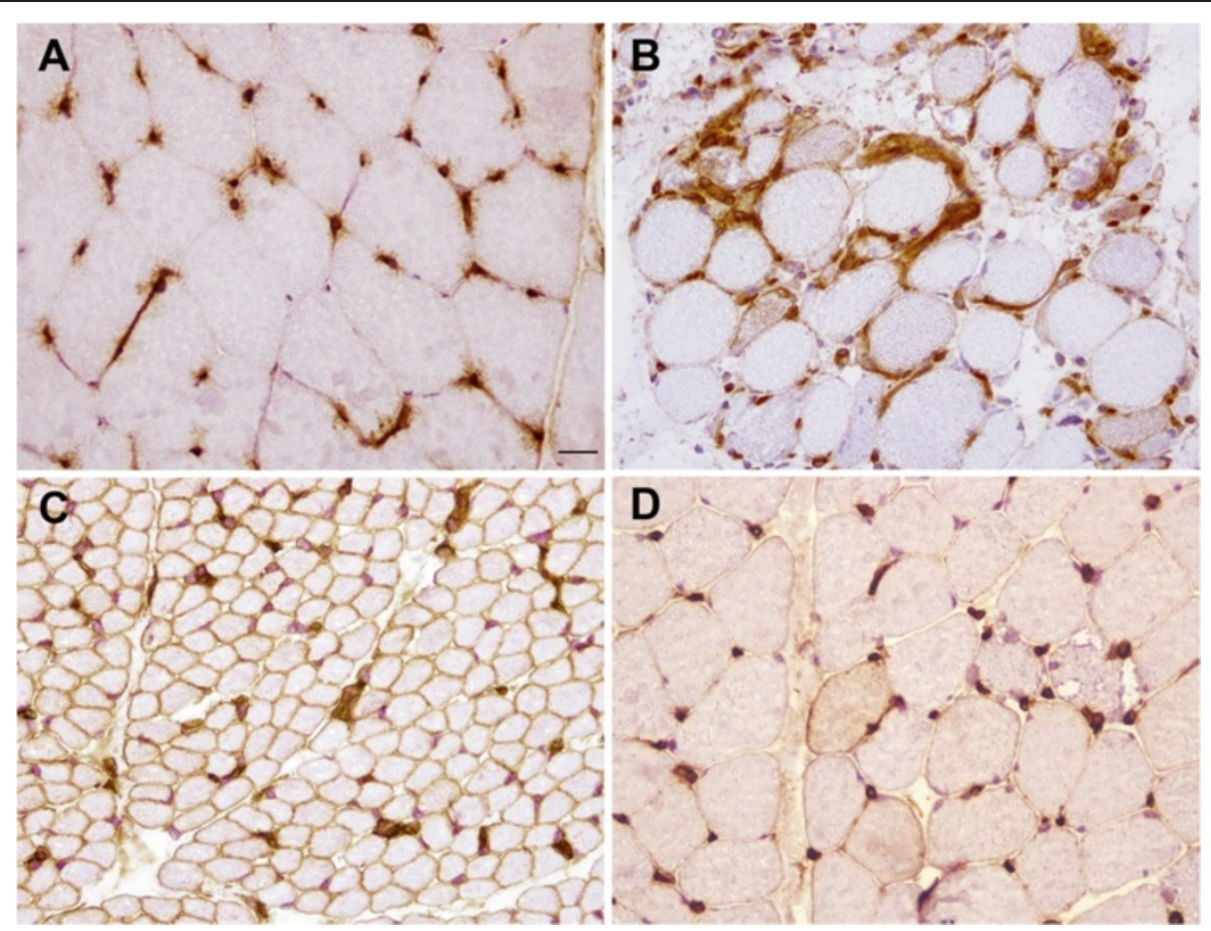

Figure 2 MHC Class I antigen (HLA) expression in (A) normal muscle, (B) muscle from patient with mutations in TK2 (P4) (C) SUCLA2 (P10) and (D) in muscle bearing a large mtDNA deletion (P7). Scale bar $=25 \mu \mathrm{m}$.

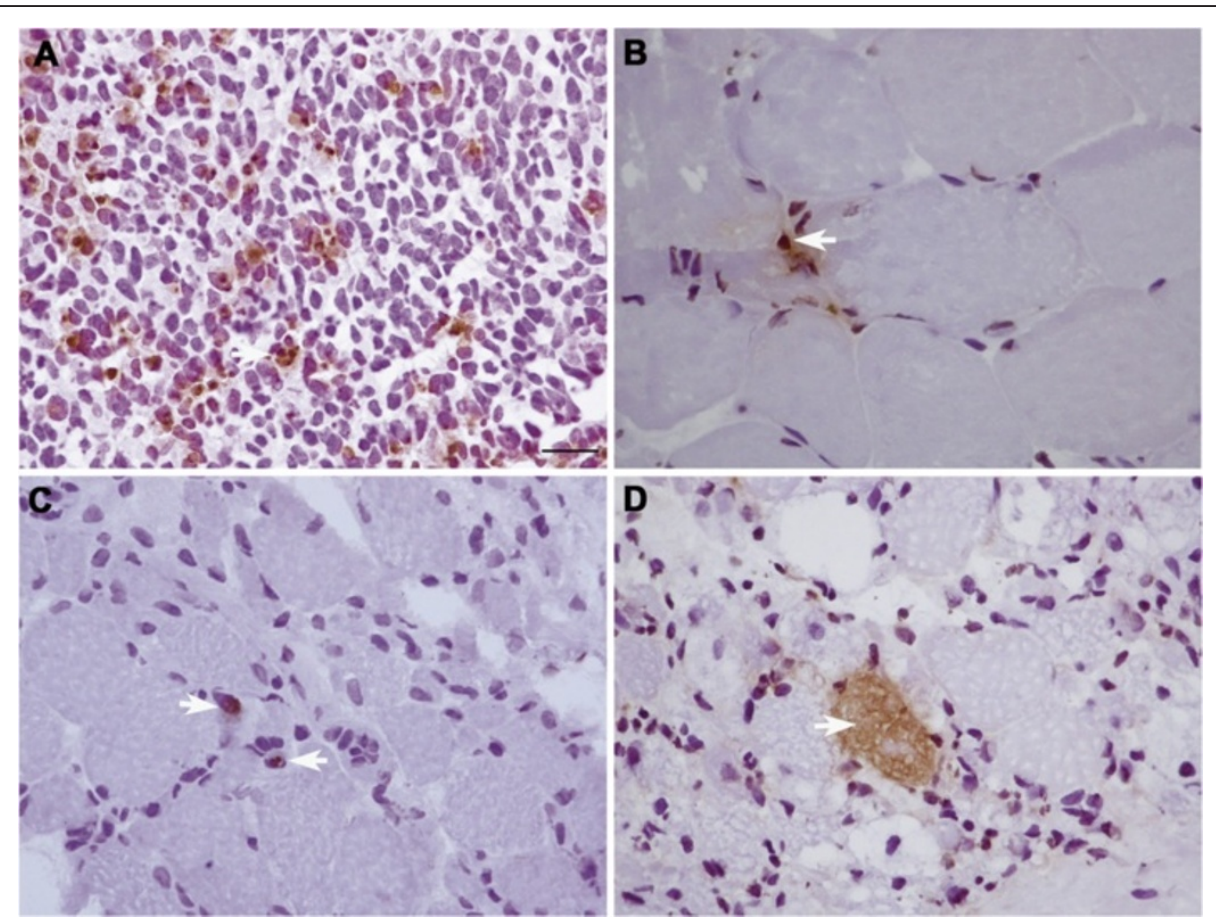

Figure 3 TUNEL assay in sections from (A) Wilms tumor and muscle from (B) P7, (C,D) (P7) patients 3 and 4 with mutations in TK2. Scale bar $=25 \mu \mathrm{m}$. 

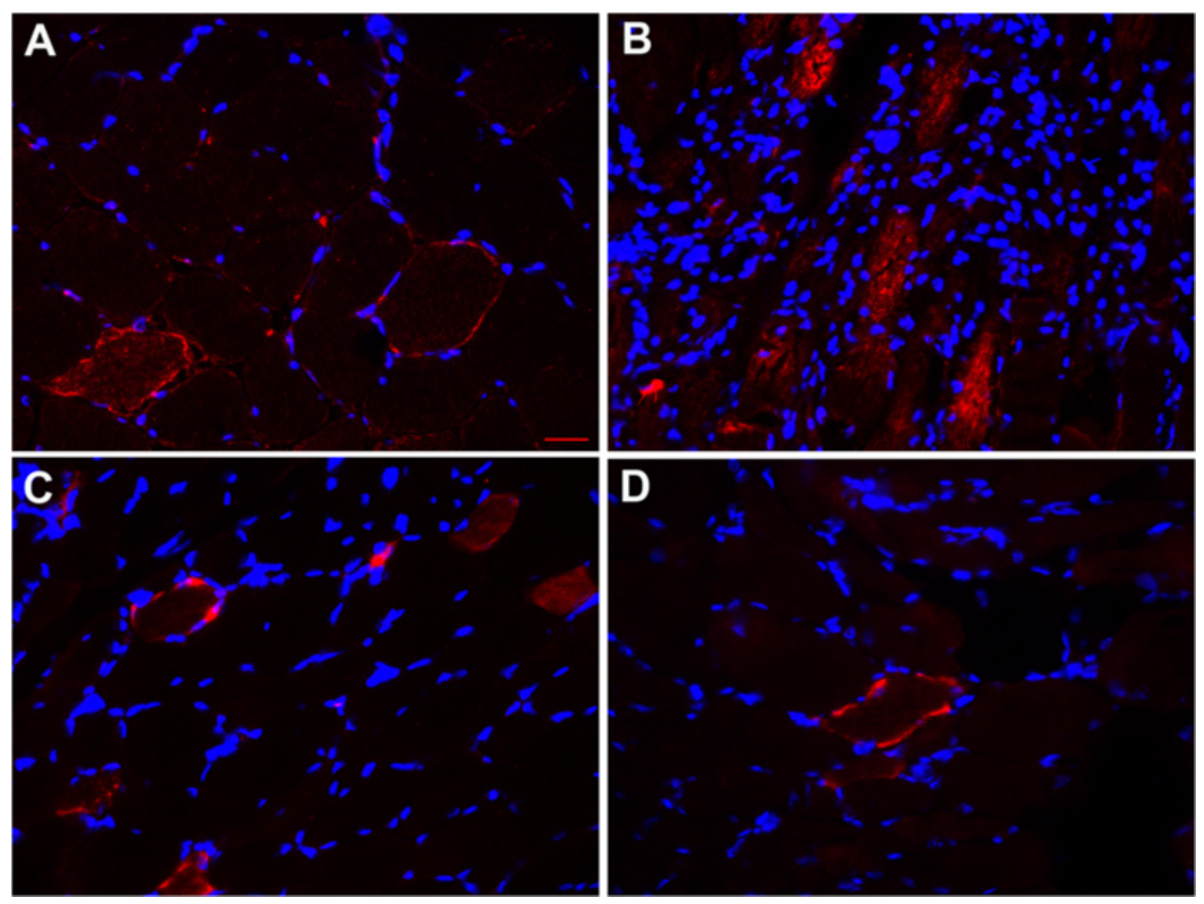

Figure 4 Caspase-3 activity. (A) P5 with a large mtDNA deletion, (B) P4 and (C,D) two consecutive biopsies of P11. Scale bar $=25 \mu \mathrm{m}$.

of mtDNA homeostasis, SHMT2 is one of the three key enzymes (together with thymidylate synthase (TYMS) and dihydrofolate reductase (DHFR) involved in de novo thymidylate biosynthesis pathway in mitochondria [25]. Thus, the upregulation of this pathway is likely to represent a mechanism to compensate for the lack of dTMP as a result of the severely reduced TK2 activity in these patients. TYMS gene expression was also increased by 1.5 fold but DHFR was not significantly changed.

The ASS1 gene $(\mathrm{FC}+4.7)$ encodes argininosuccinate synthetase-1, a cytosolic urea cycle enzyme expressed in most tissues. The enzyme is involved in the synthesis of arginine and catalyses that condensation of citrulline and aspartate to argininosuccinate using ATP. It is a key enzyme because it links the Krebs cycle with the urea cycle and pyrimidine synthetic pathway. Mutations in ASS1 cause citrullinemia type I [26]. Its induction suggests an increase in the rate of ammonia detoxification and aminoacid degradation as a source of energy. Within this category we also found ASNS $(\mathrm{FC}+7.9)$ encoding asparagine synthethase and PSAT1 $(\mathrm{FC}+4.4)$ encoding phosphoserine aminotransferase that are enzymes of the asparagine and serine biosynthetic pathways respectively.

There was an important induction of the HMGCS2 gene $(\mathrm{FC}+6.2)$ which encodes HMG-CoA synthase, as a key enzyme in ketogenesis which is a pathway to derive energy from fatty acids when blood glucose levels are low or the TCA cycle is impaired. HMGCS2 has been shown to be expressed in skeletal muscle [27] although ketogenesis only occurs in liver cells. Thus, the significance of HMGCS2 over-expression is unclear unless it is related to another yet unknown function. TRIB3 (PC+ 47) and FGF-21 $(\mathrm{FC}+10)$ are genes involved in the regulation of lipolysis upon nutrient deprivation [23].

Within the enriched GO_BPs related to glucose and glycogen metabolism we found several genes encoding for key enzymes indicating an important and coordinated attenuation of those pathways at least at the gene expression level. These included lactate dehydrogenase A ( $L D H A, \mathrm{FC}-4)$ and Phosphofructokinase-fructosebiphosphatase -1 and -3 (PFKFB1, FC -3.8; PFKFB3, $\mathrm{FC}-4.6)$. The two latter are enzymes that regulate the levels of fructose-2,6-biphosphate which is a potent stimulator of glycolysis and an inhibitor of gluconeogenesis. Thus, the activity of these enzymes regulates glucose metabolism. PFKFB1 is ubiquitously expressed whereas PFKFB3 is mainly expressed in skeletal muscle and central nervous system. It is however worth bearing in mind that gluconeogenesis takes places mainly in liver whereas it is very little active in skeletal muscle and therefore the biochemical significance of some of the observed changes at mRNA level remain unclear. PHKA1 (FC -3.6) and PHKG1 (FC -3.4) encode two out of the 16 subunits of the phosphorylase $b$ kinase enzyme which together with glycogen phosphorylase (PYGM, FC -4.8) regulates the degradation of glycogen to release glucose molecules.

Amongst the under-expressed components of the mitochondrial respiratory chain and related genes we found 
cytochrome b ( $C Y T B, \mathrm{FC}-3.3)$, mitochondrially encoded cytochrome c subunit II (COX 2, FC -3.7) and aarF domain containing kinase $3(A D C K 3, \mathrm{FC}-3.4)$ which is involved in the synthesis of Coenzyme $\mathrm{Q}$.

Regarding genes involved in nucleotide metabolism that were under-expressed it is worth mentioning guanosine monophosphate reductase (GMPR1, FC -3.3) which catalyses the irreversible NADPH-dependent reductive deamination of guanosine monophosphate (GMP) to inosine monophosphate (IMP) which is the precursor of both guanine (G) and adenine (A) nucleotides. Thus, it plays an important role in maintaining the intracellular balance of purine nucleotides.

Within the calcium/ion transport gene category of under-expressed genes we found calcium channels such as plasma membrane calcium-transporting ATPase 2 (ATP2B2, FC -3.2), calcium channel, voltage-dependent, L type, alpha $1 S$ subunit, (CACNA1S, FC -3.6), potassium channels such as ATP-sensitive inward rectifier potassium channel 12 (KCNJ12, FC -4) and sodium channels including Sodium channel voltage gated Type 1, beta subunit $(S C N 1 B, F C-5.3)$ which is the channel that serves to transmit membrane action potentials in the CNS and skeletal muscle and is localised both in plasma membrane or in the mitochondrial membrane.

\section{KEGG pathway analysis}

The DAVID functional analysis tool was used for the KEGG canonical pathways enrichment analysis using the list of differentially expressed transcripts (FDR < 0.05 , Table 2). Pathways terms with a\% FDR $<20$ were considered as significantly enriched. We obtained results in agreement to the GO_BP analysis described above (Table 4). Amongst the over-expressed genes, 12 categories were significantly over-represented (\%FDR < 20), 8 were related to immune response, 1 to aminoacid metabolism, 1 to cell adhesion, 1 to p53 signalling pathway and 1 to PPAR signalling pathway. Within the p53signalling pathway KEGG identified three additional genes which were not identified by GO: DNA damage binding protein-2 or $\mathrm{p} 48(D D B 2)$ which is expressed in a p53 dependent manner and is involved in global genome repair, tumor necrosis factor receptor superfamily $10 \mathrm{~B}$ or death receptor 5 (TNFRSF10B) which is a TRAIL receptor which engages a caspase dependent apoptosis cascade involving the intracellular adaptor FADD and is induced by DNA damage in a p53 dependent manner and thirdly, p53 effector-related to PMP22 (PERP) which is a tumor suppressor gene encoding a transmembrane protein widely expressed in response to p53. For the under-expressed genes, KEGG identified 7 significantly enriched pathways that could be grouped into those related to muscle contraction (4), sugar and glycogen metabolism (3) and calcium homeostasis (1). Thus, KEGG analysis reinforced

\section{Table 4 KEGG Pathway Enrichment Analysis for differential genes in MDS vs control muscle}

\begin{tabular}{lc}
\hline KEGG Pathway & FDR (\%) \\
\hline Over-expressed & \\
Intestinal immune network for IgA production & 0.03 \\
Systemic lupus erythematosus & 0.05 \\
Viral myocarditis & 0.09 \\
Type I diabetes mellitus & 0.10 \\
Allograft rejection & 0.33 \\
Graft-versus-host disease & 0.52 \\
Cell adhesion molecules (CAMs) & 0.67 \\
Asthma & 0.92 \\
p53 signaling pathway & 2.05 \\
Autoimmune thyroid disease & 2.20 \\
PPAR signaling pathway & 2.24 \\
Glycine, serine and threonine metabolism & 8.98 \\
Under-expressed & \\
Cardiac muscle contraction & $1.16 \mathrm{E}-04$ \\
Glycolysis/gluconeogenesis & 0.05 \\
Fructose and mannose metabolism & 0.09 \\
Hypertrophic cardiomyopathy (HCM) & 0.61 \\
Dilated cardiomyopathy & 1 \\
Calcium signaling pathway & 1.9 \\
Starch and sucrose metabolism & 2.4 \\
Arrhythmogenic right ventricular cardiomyopathy (ARVC) & 7.2 \\
\hline MDSi & \\
\hline
\end{tabular}

MDS: mitochondrial DNA depletion syndrome group. FDR: false discovery rate.

and complemented the GO data and highlighted the importance of the $\mathrm{p} 53$ pathway.

\section{Ingenuity pathways analysis (IPA)}

We applied IPA to the list of differential genes to further explore the biological significance of the expression data. IPA predicts those affected molecular functions, the upstream regulators (transcription factors) which appear to be activated within a set/group of differential genes as well as the diseases and disorders which are likely to be associated with a given expression profile (Table 5). The top 3 molecular functions associated with TK2 deficiency consisted of cell death and survival, cellular function and maintenance (related to actin cytoskeleton) and small molecule biochemistry (removal of D-glucose). Another function predicted to be activated was immune cell trafficking (containing genes for cytokines and complement system) whereas functions related to cardiovascular and skeletal system development and function were predicted to be diminished.

IPA allows the identification of the cascade of upstream transcriptional regulators (TF) that can explain the observed gene expression changes in a user's dataset. It is 
Table 5 Biological functions associated with TK2 deficiency according to Ingenuity Pathway Analysis

\begin{tabular}{|c|c|c|c|}
\hline Category & Function & P-value & mole \\
\hline \multicolumn{4}{|c|}{ Diseases and disorders } \\
\hline & Cancer & $\begin{array}{l}1.88 \mathrm{E}-14- \\
1.18 \mathrm{E}-02\end{array}$ & 253 \\
\hline & $\begin{array}{l}\text { Neurological } \\
\text { Disease }\end{array}$ & $\begin{array}{l}1.81 E-11- \\
8.60 E-03\end{array}$ & 160 \\
\hline & $\begin{array}{l}\text { Skeletal and } \\
\text { muscular } \\
\text { disorders }\end{array}$ & $\begin{array}{l}1.81 \mathrm{E}-11- \\
8.38 \mathrm{E}-03\end{array}$ & 166 \\
\hline & $\begin{array}{l}\text { Cardiovascular } \\
\text { disease }\end{array}$ & $\begin{array}{l}3.52 \mathrm{E}-09- \\
1.14 \mathrm{E}-02\end{array}$ & 10 \\
\hline & $\begin{array}{l}\text { Hereditary } \\
\text { disorder }\end{array}$ & $\begin{array}{l}\text { 6.31E-08 - } \\
1.18 E-02\end{array}$ & 98 \\
\hline
\end{tabular}

Molecular and cellular functions

$\begin{array}{ll}\text { Cell death and } & \text { 2.63E-08 - } 165 \\ \text { survival } & 1.11 \mathrm{E}-02 \\ \text { Cellular function } & 1.02 \mathrm{E}-05-135 \\ \text { and maintenance } & 1.06 \mathrm{E}-02 \\ \text { Small molecule } & 1.02 \mathrm{E}-05-105 \\ \text { biochemistry } & 1.18 \mathrm{E}-02 \\ \text { Cell signaling } & 1.17 \mathrm{E}-05-38 \\ & 1.18 \mathrm{E}-02 \\ & 1.17 \mathrm{E}-05-31 \\ \begin{array}{l}\text { Vitamin and } \\ \text { mineral } \\ \text { metabolism }\end{array} & 1.18 \mathrm{E}-02\end{array}$

Physiological system development and function

$\begin{array}{ll}\text { Skeletal and } & 1.22 \mathrm{E}-20-99 \\ \begin{array}{l}\text { muscular system } \\ \text { development and }\end{array} & 1.18 \mathrm{E}-02 \\ \text { function } & \\ \text { Embryonic } & 1.89 \mathrm{E}-05-82 \\ \text { development } & 1.18 \mathrm{E}-02 \\ \text { Organ } & 1.22 \mathrm{E}-20-80 \\ \text { morphology } & 1.18 \mathrm{E}-02 \\ \text { Organ } & 1.89 \mathrm{E}-05-63 \\ \text { development } & 1.18 \mathrm{E}-02 \\ \text { Cardiovascular } & 1.66 \mathrm{E}-07-57 \\ \text { system } & 8.20 \mathrm{E}-03 \\ \text { Development } & \\ \text { and function } & \end{array}$

based on prior knowledge of transcriptional regulators and their targets in the Ingenuity Knowledge database. When the direction of change is consistent with the literature (expression in the dataset relative to control) across the majority of targets for a given TF then the TF is predicted to be active. IPA identified TP53, TP63, HTT, TP73 and NCOA2 as the top 5 activated TF in our dataset (TK2 deficient muscle versus control muscle).

TP53, TP63 and TP73 belong to the same family and encode tumour proteins that are key regulators of cell survival and cell death. HTT encodes for Huntingtin which up-regulates the expression of Brain Derived Neurotrophic Factor (BDNF). The nuclear receptor coactivator 2 (NCOA2) is a transcriptional coregulatory protein that acylates histones, which makes downstream DNA more accessible to transcription.

IPA identified several highly connected and well scored networks of interacting genes consisting on a number of the over-expressed and under-expressed genes identified in our study (focus genes) and others that the software predicts as also forming part of the same network. Highly interconnected networks are likely to represent significant biological function, and a score is calculated as the likelihood that focus proteins are in the network due to random chance. Of particular interest was the network "Cell Death and Survival, DNA Replication, Recombination, and Repair, Cellular Response to Therapeutics" network which is shown in Figure 5. Hub genes in this network are PUMA/BBC3, PERP, BID, TNFSF10, TNFRSF10B, TP53I3, MX1, ISG15 as focus genes, and TP53, RELA, $M D M 2, C D K 2, C D K 4, Y Y 1, C A S P 3, C A S P 8$ as nonfocus genes. TP53 shows the highest connectivity as clearly revealed by the representation of the network. The cellular sub-localisation for each node, when known, is also given.

\section{Genes differentially expressed in skeletal muscle with large mtDNA deletions versus mTDNA depleted muscle Summary}

In order to discern those gene expression changes specific to mtDNA depletion and not due to generalised mitochondrial dysfunction we used muscle with large mtDNA deletions as a disease control (MDEL) since these can also present in children, affect several mtDNA genes and muscle samples are more widely accessible. Using the statistical test RankProd we identified 455 and 638 unique genes that were significantly under-expressed or over-expressed respectively (FDR $<0.05)$ in MDEL muscle relative to MDS muscle (Table 6). Thus, the expression profile of both groups of mitochondrial myopathies is markedly different. The complete list of differentially expressed genes between these two groups is shown in Additional file 3.

The Top 10 under-expressed and over-expressed genes in this comparison are listed in Table 7. The top 10 under-expressed genes coincide with genes which are very significantly over-expressed in TK2 deficient versus control muscle. This is the case for the markers of muscle fibre regeneration (MYH3, MYH8 and TNNT2) and fibrosis (COL19A1). This reflects the differences in the pathology of both forms of mitochondrial disease, muscle biopsies from patients with MDEL generally do not show proliferation of connective tissue or generation and in fact CK levels are normal whereas they are elevated in MDS patients with TK2 mutations. 


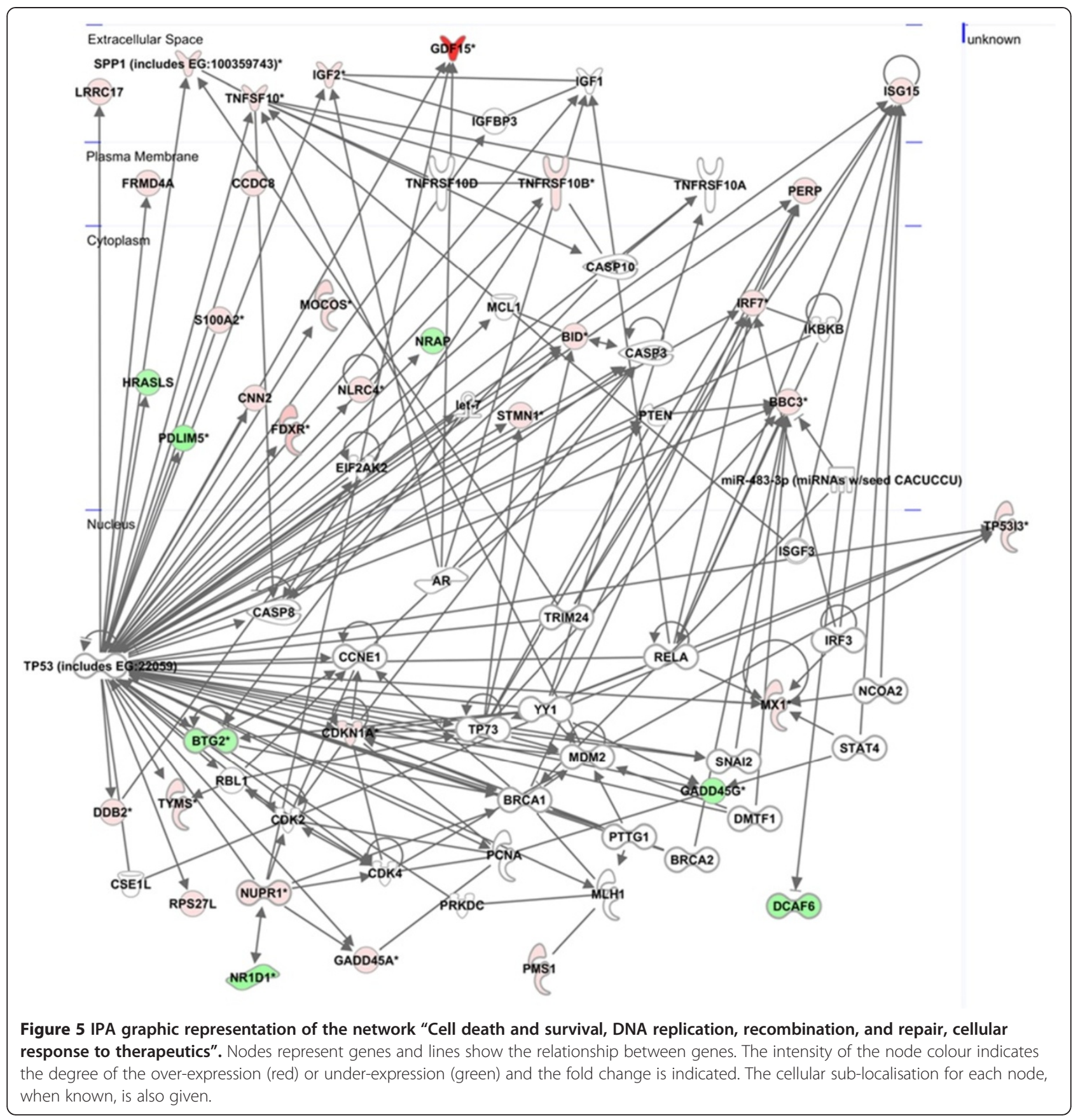

Likewise, the majority of the top 10 over-expressed genes in this comparison correspond to genes which are significantly under-expressed in TK2 deficient muscle relative to controls such as FBP2 and ATP2A1 highlighting the marked repression of those two genes (associated with attenuated glycolysis and loss of fast fibers) in the MDS group. There are however two genes which are significantly over-expressed in KSS relative to MDS which are not significantly altered in TK2 deficient muscle. These encode Keratin-associated-protein
Table 6 Summary of differential genes in MDEL vs MDS muscle

\begin{tabular}{lll}
\hline MDEL vs MDS & DOWN & UP \\
\hline FDR $<0.05$ & 455 & 638 \\
FDR $<0.05 \&$ IPA SKM & 352 & 501
\end{tabular}

Number of unique genes. MDEL: mitochondrial DNA deleted group. MDS: mitochondrial DNA depletion syndrome group. FDR: False Discovery Rate. IPA SKM: genes filtered by expression in skeletal muscle according to Ingenuity Pathway Analysis. 
Table 7 Top 10 under-expressed and over-expressed genes in MDEL vs MDS groups

\begin{tabular}{|c|c|c|c|}
\hline Gene Name & Description & FC & FDR \\
\hline \multicolumn{4}{|c|}{ Under-expressed } \\
\hline MHY3 & Myosin Heavy Chain Neonatal & -61.4 & 0 \\
\hline MHY8 & Myosin Heavy Chain Embryonic & -32.9 & 0 \\
\hline GDF15 & Growth Differentiation Factor 15 & -30.4 & 0 \\
\hline SNAR-A3 & $\begin{array}{l}\text { Small nuclear ILF3/NF90-associated } \\
\text { RNA A3 }\end{array}$ & -15.8 & 0 \\
\hline TNNT2 & Troponin T2, cardiac & -15.5 & 0 \\
\hline MYBPH & Myosin binding protein & -14.6 & 0 \\
\hline DMBT1 & Deleted in malignant brain tumors 1 & -11.8 & 0 \\
\hline LMF1 & Lipase maturation factor 1 & -10 & 0 \\
\hline COL19A1 & Collagen type XIX & -9.9 & 0 \\
\hline TRIB3 & Tribbles homolog 3 & -9.6 & 0 \\
\hline \multicolumn{4}{|c|}{ Over-expressed } \\
\hline FBP2 & Fructose-1,6-bisphosphatase 2 & 18.4 & 0 \\
\hline AQP4 & Aquaporin 4 & 17.3 & 0 \\
\hline C8ORF22 & & 14.2 & 0 \\
\hline ATP2A1 & $\begin{array}{l}\text { ATPase, Ca++ transporting, cardiac } \\
\text { muscle, fast twitch } 1\end{array}$ & 10.8 & 0 \\
\hline KRTAP3-3 & Keratin-associated-protein 3 & 10.6 & 0 \\
\hline C15ORF27 & & 8 & 0 \\
\hline CALML6 & Calmodulin like 6 & 8 & 0 \\
\hline DHRS7C & $\begin{array}{l}\text { Dehydrogenase/reductase (SDR family) } \\
\text { member } 7 C\end{array}$ & 7.9 & 0 \\
\hline MLF1 & Myeloid leukemia factor 1 & 7.1 & 0 \\
\hline TSPAN8 & Tetraspanin-8 & 7 & 0 \\
\hline
\end{tabular}

MDEL: mitochondrial DNA deleted group. MDS: mitochondrial DNA depletion syndrome group. FC: fold-change. FDR False Discovery Rate.

3 (KRTAP3-3) and an EF-hand containing $\mathrm{Ca} 2+$ binding protein, calmodulin-like 6 (CALML6).

\section{Gene ontology}

$\mathrm{GO}$ analysis revealed induction of several metabolic pathways (76 GO_BP categories\%FDR <20) in the MDEL group relative to MDS muscle (Additional file 4). 53 of those were the same GO_BPs that were repressed in MDS muscle relative to normal muscle and were mainly related to glucose and glycogen metabolism and skeletal muscle system. The remaining 23 GO_BPs were unique to the MDEL_MDS comparison. Out of those we were particularly interested in the 7 categories related to protein catabolism, the TCA cycle (3) and co-factor metabolism (4)

Within the protein catabolism category we found 40 unique genes. These encode several ubiquitin-specificproteases (UPS2, USP13, USP 15, USP24, USP25, USP38, USP47), which are responsible for the release of ubiquitin from degraded proteins, genes encoding for ubiquitinconjugating enzymes (UBE2G1, UBE2D4, UBE2D1,
$U B E 2 B, U B E 2 E 3)$, which catalyse the second step in the ubiquitination process and several components of the E3 ubiquitin- ligase complex (TRIM63, NEDD4, FEM1A, CUL3, RNF123, WWP1, DCUN1D2, RNF41).

The TCA related GO functionalities contained 6 unique genes encoding for subunits $\mathrm{B}$ and $\mathrm{C}$ of the respiratory chain complex II (SDHB and $S D H C$ ), subunits beta of succinate-CoA ligase (SUCLG2 and SUCLA2), Dihydrolipoyl dehydrogenase $(D L D)$ and isocitrate dehydrogenase (IDH2) both of which participate in pyruvate metabolism. The co-factor metabolism category included genes encoding various enzymes and co-factors such as pantothenate kinase 4 (PANK4) and phosphopantothenoylcysteine decarboxylase $(P P C D C)$, both of which participate in Coenzyme A biosynthesis, and COX10 which is important for assembly of complex IV of the respiratory chain.

There were 79 GO_BP categories significantly repressed in MDEL versus MDS group (Additional file 4). 56 of them were not induced in MDS group relative to control. Angiogenesis appeared to be attenuated in MDEL group relative to MDS with 17 unique genes significantly underexpressed including various collagen genes (COL1A1, COL1A2, COL3A1, COL5A1, COL18A1), proteoglycans (CSPG4), blood vessel survival factors (ANGPTL4), growth factors (FGF9) and early response genes downstream of growth factors such as ZFP36L1.

Thus, this GO analysis indicates that intermediate metabolism involving the TCA cycle and protein breakdown via the ubiquitin-proteasome system are significantly induced as a result of large mtDNA deletions. In contrast, angiogenesis is impaired.

\section{KEGG pathway analysis}

KEGG identified 9 canonical pathways as significantly enriched in MDEL relative to MDS including the TCA cycle (Table 8). Only 5 canonical pathways appeared attenuated in MDEL relative to MDS amongst which we found p53 signalling and two pathways related to the immune response.

\section{Meta-analysis}

In order to find out how many genes were differentially expressed in common in both the MDS and MDEL groups, relative to normal muscle, we applied the web based application BioVenn [28] which allows comparing and visualising gene lists. 79 unique genes (less than 10\% of the 804 genes) were in common (both up and down), Table 9.

These included GDF-15, haemoglobin genes (HBA2, $H B B$ and $H B D)$, inflammation related genes $(C 3, I L 17 D$, IL32, DEFB1), collagens (COL1A1, COL21A1), fatty acid transport (CD36, FABP4 and FAB5). In most cases the direction of the change was the same (up or down) but to a different degree. For example, in MDS muscle ACTN3 was 


\begin{tabular}{lc} 
Table 8 KEGG Pathway Enrichment Analysis for \\
differential genes in MDEL vs MDS muscle \\
\hline KEGG Pathway & $\%$ FDR \\
\hline Over-expressed & 0.09341201 \\
hsa04260:Cardiac muscle contraction & 0.162733253 \\
hsa04020:Calcium signaling pathway & 1.309001667 \\
hsa00010:Glycolysis / Gluconeogenesis & 4.872315134 \\
hsa00020:Citrate cycle (TCA cycle) & 4.872315134 \\
hsa00260:Glycine, serine and threonine metabolism & 6.113594087 \\
hsa05012:Parkinson's disease & 8.953173862 \\
hsa04910:Insulin signaling pathway & 13.57653918 \\
hsa05010:Alzheimer's disease & 17.58596026 \\
hsa00190:Oxidative phosphorylation & \\
Under-expressed & $1.95 \mathrm{E}-04$ \\
hsa04512:ECM-receptor interaction & 0.221772048 \\
hsa04115:p53 signaling pathway & 0.910185594 \\
hsa05322:Systemic lupus erythematosus & 3.486083165 \\
hsa04510:Focal adhesion & 5.368404888 \\
hsa04610:Complement and coagulation cascades & \\
\hline
\end{tabular}

under-expressed by almost 7 fold whereas in MDEL it was under-expressed by 3 fold. However, for a few genes the direction of the change was opposite. This is the case for aquaporin $4(A Q P 4)$ which was under-expressed (FC -6.2) in MDS muscle whereas it was over-expressed in MDEL muscle $(\mathrm{FC}+2.8)$ and also for ANGPTL4, COL1A1, C8orf22, MYH1 and IL71D (Table 8).

\section{Validation of changes in expression}

We selected some of the most significant and markedly differential genes to measure their expression levels using a quantitative PCR approach. The TK2 deficient group included three of the four samples used in the array (P2, P3 and $\mathrm{P} 4$ ). The disease control MDEL group included three of the four samples with large mitochondrial DNA deletions used in the array (P5, P6 and P7) and an additional sample (P9, Table 1). In addition we studied one patient with mutations in SUCLA-2 (P10, Table 1). Results were expressed relative to TATA box binding protein $(T B P)$ and hypoxanthine phosphoribosyltransferase 1 (HPRT1) as endogenous control genes to normalize transcription levels amongst patients. Results were analysed with qBase ${ }^{\text {plus }}$ software. FC above or below 1.5 were considered significant.

Differential expression was confirmed for all the selected genes (Table 10) although the dynamic range of differential gene expression was different for the two techniques. This was particularly true for the genes with the highest levels of over-expression, GDF-15, TRIB-3, COL19A1 and FGF21. Most genes that were changed in TK2 deficient muscle were also changed in the same direction in muscle with SUCLA2 defects, for example, the glycolytic genes FBP2, PFKFB3 and LDHA. However, there were some differences such as cytochrome b which was over-expressed instead of under-expressed as in TK2 deficient muscle.

To confirm that muscle cells are able to transcribe some of the mRNAs of interest we performed qRT-PCR using RNA from the immortalised skeletal muscle cell line LHCN-M2 (kind gift of W. Wright, UT Southwestern Medical Centre, Dallas, US, [29] after differentiation for 5 days as well as from dermal fibroblast cultures. We found that both muscle cells and fibroblast express similar levels of GDF-15 transcript (based on mean CT values) whereas fibroblast express higher levels of TRIB3 than muscle cells. When compared to normal muscle tissue, muscle cultures expressed significantly higher levels of GDF-15 but comparable levels of TRIB3 (data not shown). Thus, the source of GDF-15 could be the muscle cells themselves as opposed to the fibroblasts or other cell types present in the tissue.

\section{Expression of GDF-15 as a possible biomarker of mitochondrial disease}

Growth and differentiation factor-15 (GDF-15), also known as macrophage inhibitory cytokine-1 (MIC-1), is a member of the transforming growth factor beta (TGF- $\beta$ ) superfamily. To evaluate the potential application of GDF15 as a biomarker for mitochondrial diseases we conducted a small pilot study and measured its serum levels by ELISA. In healthy children $(\mathrm{n}=37)$ the mean concentration of GDF-15 was $380.5 \mathrm{pg} / \mathrm{mL}$ and the normal range (mean $\pm 2 \mathrm{SD}$ ) between 59 and $701 \mathrm{pg} / \mathrm{mL}$ which is comparable to what has been described in other studies $[30,31]$. We studied 13 patients with molecularly confirmed mitochondrial myopathy and although the levels of GDF-15 were highly variable they were on average very significantly increased relative to the control group (mean 3562 [SD 3973] pg/mL) $(\mathrm{p}=1.19673 \mathrm{E}-05)$ (Figure 6). The highest levels were detected in two patients with POLG mutations $(85252 \mathrm{pg} / \mathrm{mL}$ and $13215 \mathrm{pg} / \mathrm{mL}$ ) followed by $\mathrm{P} 4$ of this study carrying TK2 mutations $(8000 \mathrm{pg} / \mathrm{mL})$ and a patient with lactic acidosis and epilepsy bearing the mtDNA A3243G mutation (P12), $(6999 \mathrm{pg} / \mathrm{mL})$. GDF-15 serum levels were within the normal range (mean $320 \mathrm{pg} / \mathrm{mL}$ ) in 6 children with muscular dystrophy (DMD $\mathrm{n}=3$ and Ullrich Congenital Muscular Dystrophy $\mathrm{n}=3$ ).

In addition we measured GDF-15 levels in the conditioned medium from cultures of LHCN-M2 myotubes and normal dermal fibroblasts. We were able to detect GDF-15 in both muscle and fibroblast cultures indicating that both cell types are able to secrete it. Levels in muscle cultures were higher than in fibroblasts $(804 \mathrm{pg} / \mathrm{mL}$ and $150 \mathrm{pg} / \mathrm{mL}$ respectively). 
Table 9 List of genes differentially expressed (over and under-expressed) relative to control muscle in both MDEL and MDS muscle

\begin{tabular}{|c|c|c|c|}
\hline Gene Name & Description & FC MDS & FC MDEL \\
\hline$\overline{A C T N 3}$ & Actinin, alpha 3 & -6.9 & -2.7 \\
\hline AQP4 & Aquaporin 4 & -6.2 & +2.8 \\
\hline MARCO & Macrophage receptor with collagenous structure & -4 & -4.1 \\
\hline TNMD & Tenomodulin & -4 & -4.7 \\
\hline C8orf22 & Chromosome 8 open reading frame 22 & -4 & +3.6 \\
\hline ADAMTS8 & ADAM metallopeptidase with thrombospondin type 1 motif, 8 & -3.7 & -5.1 \\
\hline AGXT2L1 & Alanine-glyoxylate aminotransferase 2-like 1 & -3.5 & -2.5 \\
\hline SLITRK4 & SLIT and NTRK-like family, member 4 & -3.3 & -3.4 \\
\hline FNDC1 & Fibronectin type III domain containing 1 & -3.2 & -2.5 \\
\hline SERPINA5 & Serpin peptidase inhibitor, clade A (alpha-1 antiproteinase, antitrypsin), member 5 & -2.8 & -2.4 \\
\hline GAS2L2 & Growth arrest-specific 2 like 2 & -2.8 & -2.6 \\
\hline $\mathrm{MYH1}$ & Myosin, heavy chain 1 , skeletal muscle, adult & -2.7 & +2.8 \\
\hline IL32 & Interleukin 32 & -2.6 & -4 \\
\hline ITGA10 & Integrin, alpha 10 & -2.5 & -3.3 \\
\hline FMOD & Fibromodulin & -2.3 & -4 \\
\hline FOS & FBJ murine osteosarcoma viral oncogene homolog & -2.3 & +2.4 \\
\hline IL17D & Interleukin 17D & -2.3 & +2.6 \\
\hline EIF1AY & Eukaryotic translation initiation factor $1 \mathrm{~A}, \mathrm{Y}$-linked & -2.2 & -2.5 \\
\hline RPS4Y1 & Ribosomal protein S4, Y-linked 1 & -2.1 & -2.7 \\
\hline GDF15 & Growth and differentiation factor 15 & +187.9 & +6.2 \\
\hline MYH8 & Myosin heavy chain embryonic & +118.7 & +3.6 \\
\hline TRIB3 & Tribbles homologue 3 & +47.1 & +5 \\
\hline DEFB1 & Defensin beta & +16.6 & +4.5 \\
\hline Tmem63c & Transmembrane protein $63 \mathrm{C}$ & +16.2 & +2.9 \\
\hline SNORD3B-1 & Small nucleolar RNA, C/D box 3B-1 & +6.8 & +3.2 \\
\hline SNORD15A & Small nucleolar RNA, C/D box 15A & +6.3 & +3.7 \\
\hline SNORA28 & Small nucleolar RNA, H/ACA box 28 & +6.3 & +4.9 \\
\hline ATF5 & Activating transcription factor 5 & +6.3 & +2.1 \\
\hline HMGCS2 & 3-hydroxy-3-methylglutaryl-CoA synthase 2 (mitochondrial) & +6.2 & +2.7 \\
\hline GOS2 & G0/G1 switch regulatory protein & +6.1 & +4.8 \\
\hline HBA2 & Hemoglobin, alpha 2 & +5.9 & +4.5 \\
\hline XIST & X (inactive)-specific transcript (non-protein coding) & +5.8 & +4.1 \\
\hline $\mathrm{HBD}$ & Hemoglobin, delta & +5.8 & +5.3 \\
\hline C3 & Complement component 3 & +5.6 & +2.1 \\
\hline SNORA74A & Small nucleolar RNA, H/ACA box 74A & +5.6 & +2.8 \\
\hline HBB & Hemoglobin, beta & +5.5 & +4.9 \\
\hline SNORD17 & Small nucleolar RNA, H/ACA box 17 & +5.2 & +2.5 \\
\hline PRODH & Proline dehydrogenase (oxidase) 1 & +5.2 & +2.3 \\
\hline CD36 & CD36 molecule (thrombospondin receptor) & +4.7 & +2.4 \\
\hline CES1 & Carboxylesterase 1 & +4.6 & +2.9 \\
\hline SCL26A9 & Solute-linked carrier 26 alpha 9 & +4.4 & +3.6 \\
\hline FABP5 & Fatty acid binding protein 5 & +4.4 & +2.3 \\
\hline RNU105A & RNA, U105A small nucleolar & +4.3 & +2.2 \\
\hline
\end{tabular}




\begin{tabular}{|c|c|c|c|}
\hline RN7SK & RNA, 7SK small nuclear & +4.3 & +2.7 \\
\hline CIDEC & Cell death-inducing DFFA-like effector c & +3.9 & +2.6 \\
\hline FABP4 & Fatty acid binding protein 4 & +3.9 & +2.1 \\
\hline IGLL5 & Immunoglobulin lambda-like polypeptide 5 & +3.9 & +3 \\
\hline ALAS2 & Aminolevulinate, delta-, synthase 2 & +3.3 & +2.6 \\
\hline MYL10 & Myosin, light chain 10 , regulatory & +3.2 & +4 \\
\hline $\mathrm{ADH} 1 \mathrm{~A}$ & Alcohol dehydrogenase 1A (class I), alpha polypeptide & +3.1 & +3.5 \\
\hline SCARNA5 & Small Cajal body-specific RNA 5 & +2.4 & +2.4 \\
\hline SNORA81 & Small nucleolar RNA, H/ACA box 81 & +2.3 & +2.3 \\
\hline KCNE1L & KCNE1-like & +3 & +2.6 \\
\hline RBP4 & Retinol binding protein 4 & +2.9 & +3 \\
\hline GZMH & Granzyme H (cathepsin G-like 2, protein h-CCPX) & +2.9 & +2.3 \\
\hline HBG1 & Hemoglobin, gamma A & +2.7 & +3.6 \\
\hline DPYSL4 & Dihydropyrimidinase-like 4 & +2.6 & +3.1 \\
\hline FMO2 & Flavin containing monooxygenase 2 & +2.5 & +2.6 \\
\hline C20orf26 & Chromosome 20 open reading frame 26 & +2.5 & +3.5 \\
\hline HIST1H4L & Histone cluster $1, \mathrm{H} 4 \mathrm{I}$ & +2.5 & +2.7 \\
\hline SCARNA16 & Small Cajal body-specific RNA 16 & +2.5 & +3.9 \\
\hline COL21A1 & Collagen, type XXI, alpha 1 & +2.4 & +2.7 \\
\hline ANGPTL4 & Angiopoietin-like 4 & +2.4 & -3.5 \\
\hline RNU1-5 & RNA, U1 small nuclear 5 & +2.3 & +3.8 \\
\hline COL1A1 & Collagen, type I, alpha 1 & +2.1 & -4.2 \\
\hline RNU2-2 & RNA, U2 small nuclear 2 & +2 & 1.9 \\
\hline
\end{tabular}

\section{Discussion}

High-sensitivity microarray technology provides a useful tool to study changes in the whole transcriptome of skeletal muscle samples in relation to specific genetic or biochemical mitochondrial defects [32]. This is the first report of global gene expression analysis of TK2 deficient human skeletal muscle. There is a previous study of gene expression in fibroblasts from patients with TK2 or dGUOK mutations [33]. Using this approach we have detected significant changes in a set of over 700 genes which represents the adaptative response of skeletal muscle cells to TK2 defects and the subsequent severe mtDNA depletion. Furthermore, we have also identified changes in common with another form of mitochondrial myopathy that also affects various mtDNA encoded components of the respiratory chain. These two pathologies only share a small proportion of differential genes compared with normal muscle which indicates that the cell responds differently to various forms of mitochondrial dysfunction and that the changes that we have observed are specific to TK2 deficiency.

Our data indicate that TK2 deficiency results in important changes in genes involved mainly in metabolism, regulation of the cell cycle and mitochondrial DNA maintenance, oxidative stress and apoptosis.

\section{Metabolism}

We found over-expression of several transcripts involved in the starvation response. These include ASNS, PSAT1, FGF-21 and TRIB3. These genes, which were also overexpressed in twinkle deficient mouse skeletal muscle [34], have in common the presence of an amino acid response element (AAREs) in their promoter region where transcription factors of the ATF family bind to induce their expression upon limited nutrition [35]. Thus, these results suggest that TK2 deficiency induces a starvation-like response which alters lipid and aminoacid metabolism.

Two out of the three key enzymes of the de novo thymidine nucleotide synthesis pathway were co-ordinately over-expressed in the array, SHMT2 and TYMS. Coordinated expression of both proteins, but not of the third enzyme in the pathway, dihydrofolate reductase (DHFR), has been previously reported [36]. This may represent a compensatory mechanism for defective salvage pathway due to the severe reduction of TK2 activity. 
Alternatively, it may reflect the fact that there is an increase in regenerating cycling muscle cells which rely on de novo synthesis as opposed to non-regenerating muscle which is considered post-mitotic and thus depends mainly on the salvage pathway.

\section{P53, mitochondrial DNA maintenance, cell cycle and oxidative stress}

TP53 gene encodes p53, a tumor suppressor gene which is activated by several forms of cellular stress such as DNA damage, oxidative stress, ribonucleotide depletion and mitochondrial dysfunction as well as by other stimuli [37]. P53 plays a crucial role in the regulation of the cell cycle, DNA repair and apoptosis [38]. Under conditions of oxidative stress, p53 traslocates to mitochondria where it binds the mitochondrial DNA polymerase ( $\mathrm{Pol} \gamma$ ) and the mitochondrial transcription factor A (TFAM gene) and promotes base excision repair and/or replication of mtDNA. Treatment of cells with $\mathrm{N}$-acetylcysteine (anti-oxidant) prevents traslocation of p53 to mitochondria [39].

In the present study we have demonstrated activation of several genes and pathways regulated by p53. PIG3, encoding TP53I3, a NADPH dependent medium chain dehydrogenase reductase (quinone reductase) was amongst the over-expressed p53 targets. PIG3 expression can also be activated by p63 and p73 (which are also predicted to be activated in our data set) [40]. TP53I3 plays a dual role. On the one hand as a ROS producer upon induction by p53 to promote apoptosis and on the other hand as a DNA breaks sensor that activates the DNA damage response pathway (DDR pathway) after translocation to the nucleus. In normal cells subjected to genotoxic stress, the DDR pathway stabilises p53 which induces PIG3 transcription. If the damage is not excessive PIG3 produces certain amounts of ROS insufficient to induce the expression of other pro-apoptotic genes but also promotes DNA repair. If the damage cannot be repaired very high levels of PIG3 produce very high levels of ROS and finally trigger apoptosis [40]. It is interesting to mention that TP53I3 gene is within a genomic region identified by Calvo et. al as being linked to mitochondrial disease [4]. Although mutations in TP53I3 gene have not been identified in humans, a role for cancer predisposition of certain polymorphisms has been proposed.

We found over-expression of cyclin dependent kinase inhibitor 1 (CDKN1A) and growth arrest and DNAdamage-inducible alpha (GADD45A) both of which are known to prevent progression of the cell cycle at the G1 and G2 level respectively and are downstream targets of p53 [41] (Zhang and Chen 2008).

Thus, we hypothesise that mtDNA depletion leads to p53 activation to promote mtDNA replication and repair both via its role as a transcription factor and via its interaction with Pol $\gamma$ and mtTFA in mitochondria.
On the other hand, mitochondrial dysfunction and subsequent reactive oxygen species accumulation amplifies the p53 signalling cascade which induces the expression of pro-apoptotic factors, activation of caspase- 3 and apoptosis in damaged cells.

The p53 pathway has been previously associated with mitochondrial DNA depletion. On the one hand, p53 deficient mouse and human fibroblasts show reduced mtDNA copy number [42].On the other hand, mutations in $R R M 2 B$ cause a severe subtype of MDS which mainly affects skeletal muscle and kidney [7]. $R R M 2 B$ encodes the R2 subunit of the p53-inducible ribonucleotide reductase which converts ribonucleoside diphosphates into the corresponding deoxyribonucleosides which is essential for DNA repair [43]. Mutations in RRM2B null mice suffer from renal failure, growth retardation, and early mortality and show decreased mtDNA content in kidney, muscle and liver [43]. In the present study we did not find increased expression of $R R M 2 B$ but its activation via posttranscriptional mechanisms cannot be excluded.

Progressive muscle fibre loss is a feature of muscle biopsies from patients with TK2 defects. Apoptosis has been described in various neuromuscular conditions [44] including some mitochondrial myopathies [45]. Mitochondria play a key role regulating the susceptibility of cells to undergo apoptosis because they are involved in oxidative stress, $\mathrm{Ca}^{2+}$ homeostasis and energy supply and several of the pro- or anti-apoptotic factors localise to mitochondria. In the present study we have demonstrated for the first time evidence of over-expression of several pro-apoptotic factors (some of which are regulated by p53), caspase-3 enzymatic activation and DNA fragmentation in human skeletal muscle deficient for TK2. Anti-apoptotic drugs have been shown to prevent apoptosis, ameliorate muscle histology, slow loss of muscle fibres and increase body weight and survival in animal models for congenital muscular dystrophy and some of these drugs are under consideration for clinical trials in humans [46]. In view of our results, the use of such compounds may also be beneficial in TK2 deficient muscle to prevent rapid muscle loss.

\section{P53, glucose metabolism and oxidative phosphorylation}

In addition to its role as "guardian" of the genome, p53 is emerging as a key regulator of many metabolic processes including glycolysis, oxidative phosphorylation, insulin sensitivity and mitochondrial stability [47]. P53 induces the expression of TP53-induced glycolysis and apoptosis regulator (TIGAR) which affects FBP2 (fructose-2,6-biphosphatase), which was under-expressed at the RNA level in our microarrays, and limits the activity of phosphofructokinase 1 thus lowering the rate of glycolysis. In this way, some glycolytic intermediates can be utilized in the pentose phosphate pathway which feeds into de novo nucleotide 
Table 10 Validation of microarray results with real time PCR

\begin{tabular}{|c|c|c|c|c|c|c|}
\hline \multirow[b]{2}{*}{ Gene } & \multirow[b]{2}{*}{ Description } & \multicolumn{2}{|c|}{ MDS } & \multicolumn{2}{|c|}{ MDEL } & \multirow{2}{*}{$\begin{array}{c}\text { SUCLA-2 } \\
\text { FC Fluidigm }\end{array}$} \\
\hline & & FC array & FC Fluidigm & FC array & FC Fluidigm & \\
\hline FBP2 & fructose-1,6-bisphosphatase 2 & -9.1 & -23.4 & ns & -1.18 & -1.59 \\
\hline ATP2A1 & ATPase, $\mathrm{Ca}++$ transporting, cardiac muscle, fast twitch 1 & -9.1 & -13.3 & ns & 1.07 & 1.31 \\
\hline PFKFB3 & Phosphofructokinase-biphosphatase-3 & -4.6 & -1.7 & ns & -1.14 & -2.32 \\
\hline LDHA & Lactate-dehrydrogenase-A & -4.1 & -7.9 & ns & -1.67 & -2.85 \\
\hline ADCK3 & aarF-domain-containing kinase 3 & -3.4 & -2.7 & ns & -1.21 & 1.19 \\
\hline CYTB & Cytochrome b & -3 & -7.63 & ns & -1.32 & 3.44 \\
\hline GDF15 & Growth Differentiation Factor 15 & 188 & 845 & 6 & 154.6 & 2.46 \\
\hline TRIB3 & Tribbles homolog 3 & 47 & 141.3 & 5 & 29.5 & 2.92 \\
\hline TNNT2 & Troponin T2, cardiac & 21 & 35.9 & ns & 7.3 & 6.62 \\
\hline COL19A1 & Collagen type XIX & 11 & 100.6 & ns & 19.7 & 1.66 \\
\hline FGF21 & Fibroblast Growth Factor 21 & 10.8 & 1281.1 & ns & 286.8 & - \\
\hline HMGCS2 & 3-hydroxy-3-methylglutaryl-CoA synthase 2 & 6.2 & 9.2 & 2.7 & 4.99 & 66.85 \\
\hline PTPRF & Receptor-type tyrosine-protein phosphatase $F$ & 6.1 & 9.6 & ns & 2.09 & 3.2 \\
\hline GOS2 & G0/G1 switch regulatory protein & 6.1 & 1.91 & 4.8 & 2.21 & 1.5 \\
\hline SHMT2 & Serine hydroxyl-methyltransferase 2 & 3.4 & 4.8 & ns & 1.84 & -1.06 \\
\hline ASS1 & argininosuccinate synthase- 1 & 4.7 & 3.1 & ns & 1.53 & 3.52 \\
\hline TP5313 & TP53 induced gene 3 & 3.5 & 2.42 & ns & -1.30 & 1.54 \\
\hline DPYSL4 & Dihydropyrimidinase-related protein 4 & 2.6 & 5.48 & 3.1 & 1.30 & - \\
\hline TP53 & & ns & 1.8 & ns & 1.01 & 1.61 \\
\hline PPARG & Peroxisome proliferator-activated receptor gamma & ns & -1.02 & ns & -1.10 & 1.54 \\
\hline SUCLA2 & succinate-CoA ligase, ADP-forming, beta subunit & ns & -2.28 & ns & -1.29 & -1.35 \\
\hline TK2 & Tymidine kinase 2 & ns & -1.19 & ns & -1.24 & 1.37 \\
\hline
\end{tabular}

synthesis. P53 is also known to induce the expression of Apoptosis Inducing Factor (AIF), which is essential for complex I function [47] and of its mitochondrial homologue AIFM2 which was over-expressed $(\mathrm{FC}+2.6)$ in our microarrays Thus, it would seem that in the context of TK2 deficiency, p53 may be inhibiting glycolysis and promote de novo nucleotide synthesis. We cannot exclude that some of the observed changes are associated with selective loss of type II fibres.

\section{GDF-15}

In humans, GDF-15 is predominantly expressed in the placenta, with low levels in the kidney, pancreas, and prostate. However, its expression can be rapidly induced by cytokines such as interleukin-1 and TGF- $\beta$ [48]. GDF-15 has diverse biological functions. Early studies have shown that low serum GDF-15 levels correlate with miscarriages, indicating that it might be able to suppress inflammation in early pregnancy [49]. GDF-15 also plays an important role in tumorigenesis and metastasis since it is dramatically increased in many types of cancers [50]. The expression of GDF-15 is strongly induced by p53 and anti-tumorigenic agents, such as the non-steroidal anti-inflammatory drugs [51]. Serum GDF-15 concentrations have been shown to be also associated with the risk of acute coronary syndrome as well as its prognosis. GDF-15 can be produced by cardiac myocytes in response to ischemia, nitrosative or oxidative stress and angiotensin II [22].

GDF-15 mRNA was dramatically increased (by almost $200 \times$ ) in TK2 deficient muscle and it was also elevated in mtDNA deleted muscle (by 6 fold). We confirmed its over-expression by qRT-PCR in muscle tissue and also in the LHCM-N2 cell line demonstrating that skeletal muscle cells can transcribe this gene. Using ELISA we demonstrated that LHCN-M2 synthesise and secrete GDF-15 to the extracellular space. Thus, GDF-15 could be produced by muscle cells in vivo in response to oxidative stress and p53 activation. However, contribution from other cell types cannot be excluded.

We conducted a small pilot study to evaluate the potential application of GDF-15 as a biomarker of mitochondrial disease by measuring its serum concentration by ELISA. We established the normal range in our population of healthy children and studied serum from patients with genetically confirmed mitochondrial disease. On average, GDF15 levels in patients were 9 times higher than in the healthy control group. Two patients had values that fell within the broad normal range that we established (mean $\pm 2 \mathrm{SD}$ ). 


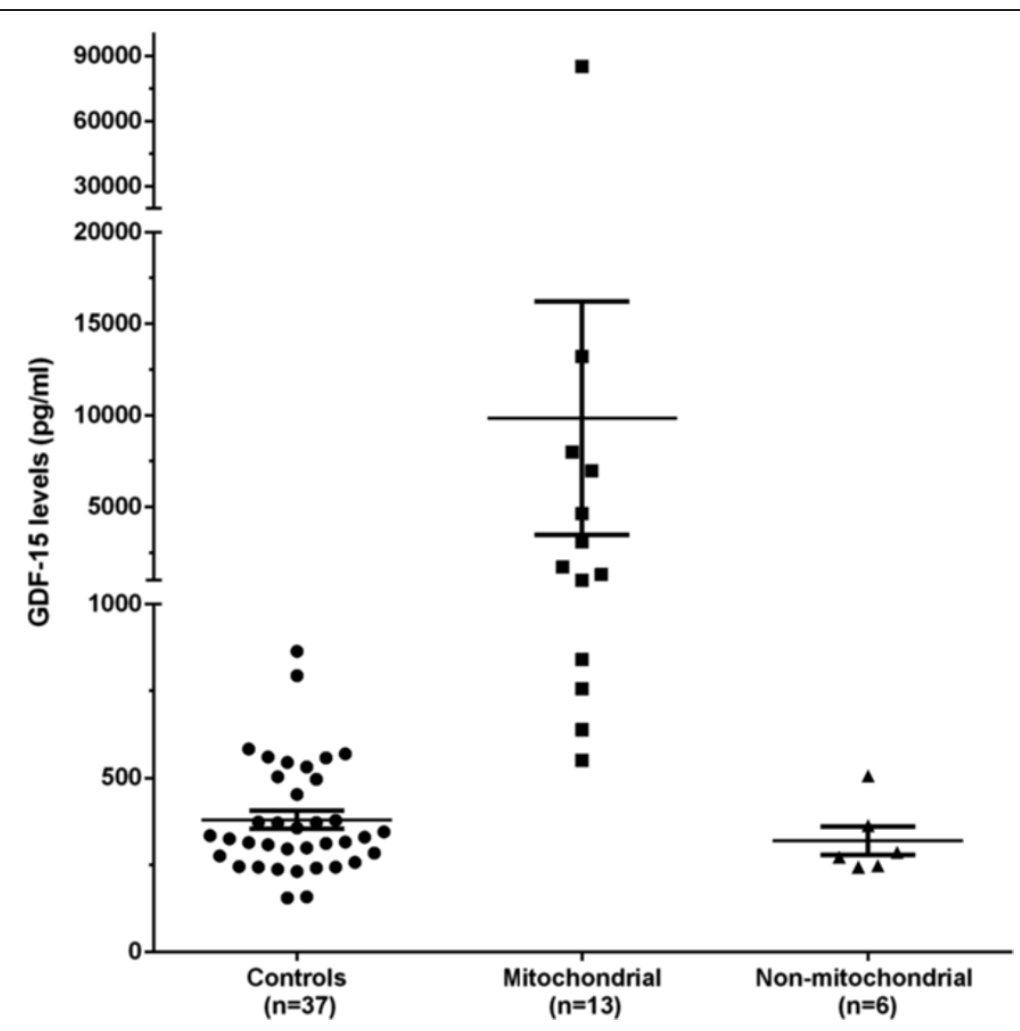

Figure 6 GDF-15 serum levels as measured by ELISA (pg/ml) in unaffected children (circles) and children with mitochondrial myopathies (squares).

Nonetheless the GDF-15 concentration was 1.7 and 1.5 times higher than the normal mean value and would fall within a smaller range (mean $\pm \mathrm{SD})$. We also included 6 non-mitochondrial myopathies children with severe dystrophies whose GDF-15 values were normal. We are currently extending this study to include more patients with mitochondrial diseases (with and without myopathy), non-mitochondrial myoapthies and various neurometabolic disorders, to correlate GDF-15 plasma levels with other biochemical markers (in particular FGF-21, lactate, pyruvate, lactate to pyruvate ratio and creatine kinase values) [52] as well as with muscle histopathological markers such as COX negative and/or ragged-red fibres.

In spite of the limited number of patients and disease controls and the necessity for a larger study, the mRNA and protein data strongly suggest that GDF-15 (alone or in combination with other markers) may serve as a biochemical marker to aid in the diagnosis of mitochondrial diseases.

\section{Conclusions}

The integrated use of Gene Ontology, KEGG pathways, IPA databases and statistical and visualization tools has allowed us to place the differential gene expression data obtained from the microarrays into a coherent functional context. Our data suggest that mtDNA depletion due to TK2 defects leads to activation of p53 signalling pathway. P53 induction may represent a compensatory mechanism to promote DNA repair and replication in mitochondria. In addition, p53 inhibits glycolysis to promote the pentose synthetic pathway. The inability of some muscle cells to replenish the dNTPs pools and overcome the loss of mtDNA beyond a certain level (despite the observed upregulation of two key enzymes of the de novo synthesis pathway) is likely to result in sustained ROS production by TP53I3 and activation of other pro-oxidative and pro-apoptotic factors which lead to the death of a proportion of muscle fibres. P53 and oxidative stress probably induce the expression and secretion of GDF-15 into the circulation. This finding may be exploited as a tool for diagnosis of mtDNA depletion and other mitochondrial myopathies although further studies are required.

\section{Methods}

\section{Ethics statement}

This work has been approved by the Ethical Committee of "Fundació Sant Joan de Déu".

Written informed consent for research was obtained from all patients (or their parents/guardians) according to the Hospital Sant Joan de Déu forms and regulations. 


\section{Muscle biopsies}

Open muscle biopsies (from left quadriceps or deltoid muscles) were performed, oriented and frozen according to standard procedures [53]. Lower limb muscle samples were obtained from children non-affected by a neuromuscular disease (control muscle group) who underwent orthopaedic surgery at the Hospital Sant Joan de Déu.

\section{RNA preparation}

Total RNA was extracted from biopsies $(30 \mathrm{mg}$ ) or cells with RNeasy Fibrous Tissue mini kit (Qiagen, Hilden, Germany). Muscle tissue was homogenized with TissueRuptor (Qiagen, Hilden, Germany) following the manufacturer's instructions. Quantity and quality of RNA obtained was determined with Nanodrop 8000 Spectrophotometer (Thermo Scientific, Schwerte, Germany) and its integrity with Agilent 2100 Bioanalyzer (Agilent technologies, Waldbronn, Germany). In all samples RNA integrity numbers (RIN) were $>7$ and 260/280 ratios near 2.0. $0.15 \mathrm{mg}$ of RNA was retro-transcribed with SuperScript III FirstStrand Synthesis Super-Mix for qRT-PCR (Invitrogen ${ }^{\mathrm{Tm}}$, Carlsbad, CA, USA) to obtain cDNA and then was amplified with Taqman PreAmp Master Mix (Applied Biosystems, Foster City, CA, USA) following manufacturer's instructions.

\section{Microarray experiments}

Cyanine-3 (Cy3) labeled cRNA was prepared from 100 ng of RNA using the LowInputQuick Amp Labeling kit (Agilent technologies, Waldbronn, Germany) according to the manufacturer's instructions, followed by RNAeasy column purification (Qiagen, Hilden, Germany). Dye incorporation and cRNA yield were checked with the NanoDrop ND-1000 Spectrophotometer. 600 ng of Cy3labelled cRNA (specific activity $>10.0 \mathrm{pmol}$ Cy3/ug cRNA) was fragmented at $60^{\circ} \mathrm{C}$ for 30 minutes in a reaction volume of $25 \mathrm{ul}$ containing $1 \times$ Agilent fragmentation buffer and $2 \times$ Agilent blocking agent following the manufacturer's instructions. On completion of the fragmentation reaction, 25 ul of $2 \times$ Agilent hybridization buffer was added to the fragmentation mixture and hybridized to Agilent SurePrint G3 Human Gene Expression $8 \times 60 \mathrm{~K}$ arrays (G4851A028004, Agilent technologies, Waldbronn, Germany) for 17 hours at $65^{\circ} \mathrm{C}$ in a rotating Agilent hybridization oven. After hybridization, microarrays were washed 1 minute at room temperature with GE Wash Buffer 1 and 1 minute with37 ${ }^{\circ} \mathrm{CGEW}$ ashbuffer2(Agilenttechnologies, Waldbronn, Germany). Scanned on an Agilent G2539A scanner at 3um resolution and 100\%PMT. The intensity data of each individual hybridization were extracted and the quality was assessed with the Feature Extraction software 10.7 (Agilent technologies, Waldbronn, Germany). Raw data was corrected for background noise using the Normexp method.
Quantile normalization method was applied to assure comparability across samples [54].

\section{Microarray statistical analysis}

Statistical differential gene expression analysis between groups was performed by the non-parametric approach Rank Prod [55] which detects genes that are consistently highly ranked in a number of replicate experiments, a method that has shown robustness to outliers and being particularly powerful when small number of replicates is available. Those oligonucleotides that present changes between groups with FDR (false discovery rate) value lower than 0.05 were considered significant. The tool DAVID [24] was used for the calculation of the functional overrepresentation statistics of the different lists of significant genes obtained with Rank Prod analysis. Gene Ontology Biological Process and KEGG pathways data bases (Kyoto Encyclopedia of Genes and Genomes, Kanehisa, Goto et al., 2002) were considered. Also, interaction networks have been constructed using the Ingenuity Pathways Analysis tool (IPA, http://www.ingenuity.com), based on extensive records maintained in the Ingenuity Pathways Knowledge Base (IPKB).

\section{Real time quantitative RT-PCR}

High-throughput real-time qPCR was performed according to the manufacturer's protocol on the BioMark 48.48 Dynamic Array (Fluidigm, South San Francisco, CA, USA) with Taqman Gene Expression Assays (Applied Biosystems, Foster City, CA, USA), (Table 11). qRT-PCR was run in triplicates in all samples and TBP and HPRT1 were used as endogenous control genes to normalize transcription levels amongst patients. Results were analyzed with qBase ${ }^{\text {plus }}$ software (Biogazelle, Zwijnaarde, Belgium).

\section{Immunohistochemistry and immunofluorescence}

Cryosections ( $7 \mu \mathrm{m}$ thick) were labelled without prior fixation using primary antibodies diluted in PBS $0.1 \%$ Tween-20. Immunofluorescence was visualised with species-specific secondary antibodies directly linked to Alexa-fluorophores (Molecular Probes, Eugene, OR, USA). Nuclei were visualised using DAPI (Molecular Probes, Eugene, OR, USA) diluted in PBS 0.1\% Tween20. Immunohistochemistry was performed using NovoLink peroxidase detection kit according to manufacturer's instructions (Novo-Link peroxidase detection kit, Leica Microsystems, Wetzlar, Germany). We used mouse monoclonal antibody against MHC Class I (Dako, Glostrup Denmark, Cat. M0736, 1:1000) and rabbit polyclonal antibody against active caspase-3 (Pharmingen, San Diego, CA, USA, Cat. 559565, 1:400). Non-specific labelling was assessed using sections incubated without primary antibodies. Immunofluorescence was visualised under a conventional epifluorescence microscope (Leica DM5000B). 
Table 11 qRT-PCR primers

\begin{tabular}{|c|c|c|}
\hline Gene name & Gene symbol & Taqman gene expression assays \\
\hline TATA box binding protein & TBP & Hs99999910_m1 \\
\hline Hypoxanthine phosphoribosyltransferase 1 & HPRT1 & Hs02800695_m1 \\
\hline Actin, beta & ACTB & Hs01060665_g1 \\
\hline Desmin & DES & Hs00157258_m1 \\
\hline 3-hydroxy-3-methylglutaryl-CoA synthase 2 (mitochondrial) & HMGCS2 & Hs00985427_m1 \\
\hline Serine hydroxymethyltransferase 2 (mitochondrial) & SHMT2 & Hs00193658_m1 \\
\hline Argininosuccinate synthase 1 & ASS1 & Hs01597989_g1 \\
\hline Tumor protein p53 inducible protein 3 & TP5313 & Hs00153280_m1 \\
\hline Complement component 3 & C3 & Hs00163811_m1 \\
\hline Tumor protein p53 & TP53 & Hs01034249_m1 \\
\hline Hemoglobin, beta & $\mathrm{HBB}$ & Hs00758889_s1 \\
\hline G0/G1switch 2 & GOS2 & Hs00274783_s1 \\
\hline Collagen, type XIX, alpha1 & COL19A1 & Hs00156940_m1 \\
\hline Protein tyrosine phosphatase, receptor type, F & PTPRF & Hs00892965_m1 \\
\hline Peroxisome proliferator-activated receptor gamma & PPARG & Hs01115513_m1 \\
\hline Fructose-1,6-bisphosphatase 2 & FBP2 & Hs00427791_m1 \\
\hline Cytochrome b & MT-CYB & Hs02596867_s1 \\
\hline Lactate dehydrogenase A & LDHA & Hs00855332_g1 \\
\hline aarF domain containing kinase 3 & ADCK3 & Hs00220382_m1 \\
\hline Troponin T type 2 (cardiac) & TNNT2 & Hs00165960_m1 \\
\hline ATPase, Ca++ transporting, cardiac muscle, fast twitch 1 & ATP2A1 & Hs01092295_m1 \\
\hline Dihydropyrimidinase-like 4 & DPYSL4 & Hs01067761_m1 \\
\hline Fibroblast growth factor 21 & FGF21 & Hs00173927_m1 \\
\hline Tribbles homolog 3 (Drosophila) & TRIB3 & Hs01082394_m1 \\
\hline Growth differentiation factor 15 & GDF15 & Hs00171132_m1 \\
\hline 6-phosphofructo-2-kinase/fructose-2,6-biphosphatase 3 & PFKFB3 & Hs00998700_m1 \\
\hline Succinate-CoA ligase, ADP-forming, beta subunit & SUCLA2 & Hs00605838_g1 \\
\hline Thymidine kinase 2, mitochondrial & TK2 & Hs00177950_m1 \\
\hline
\end{tabular}

Images were acquired with Leica Imaging Suite (Leica Microsystems, Wetzlar, Germany) and were quantified with ImageJ software (http://rsbweb.nih.gov/ij/).

\section{TUNEL Assay}

The TUNEL assay was employed to examine apoptosis via DNA fragmentation using the ApopTag Plus Peroxidase In Situ Apoptosis Detection Kit (Millipore Corporation, Billerica, MA, USA, Cat. S7101) according to manufacturer's instructions.

\section{GDF-15 serum levels}

We analysed serum samples collected from patients and controls of paediatric age. We measured GDF-15 concentration in duplicate samples using the human GDF-15 Quantikine ELISA kit (R\&D Biosystems, Minneapolis, US) according to Manufacturer's instructions. The values from each assay were extrapolated from a standard four parameter logistic (4-PL) curve fit. Since serum samples were diluted, the concentration read from the standard curve was multiplied by 4 to obtain the final $\mathrm{pg} / \mathrm{mL}$ concentration.

\section{Statistical analysis}

Average values are expressed as mean \pm standard error (MEAN $\pm \mathrm{SE}$ ). Significance was tested by Student unpaired $t$-test and $P$-value $<0.05$ was considered as significant (NS, non-significant, ${ }^{*} P<0.05,{ }^{* *} P<0.01$ and $\left.{ }^{* * * *} P<0.001\right)$.

\section{Availability of supporting data}

Gene expression data has been deposited at the National Centre for Biotechnology Information Gene Expression Omnibus (GEO) database as GEO Series accession number GSE43698. 


\section{Additional files}

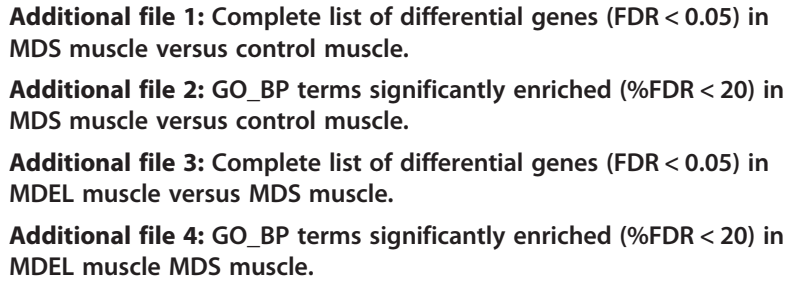

\section{Abbreviations}

mtDNA: Mitochondrial DNA; MDS: Mitochondrial DNA depletion syndrome; TK2: Thymidine kinase; FDR: False-discovery-rate; FC: Fold-change; GO: Gene ontology; IPA: Ingenuity Pathway Analysis; GDF-15: Growth and differentiation factor 15; CPEO: Chronic progressive external opthalmoplegia; KSS: Kearns-Sayre syndrome.

\section{Competing interest}

The authors declare that they have no competing interests.

\section{Authors' contributions}

Contributions to study conception and design, data acquisition, analysis and interpretation, draft preparation, revision and approval: KSG, PS, JMC. Contributions to data acquisition, analysis and interpretation, draft preparation, revision and approval: JC, Fl, AR, BDP, NA, OC, CJ Contributions to data acquisition, analysis and interpretation, draft revision and approval: MM, RM, JVM, SM, MM, FG, DML, RQM, MF, MJ, LGE, RPE, MR, TF. All authors read and approved the final manuscript.

\section{Acknowledgements}

This work is funded by the Ministerio de Ciencia e Innovación \& Instituto de Salud Carlos III, Spain (Ref CP09/00011). Muscle biopsy samples of patient 1 and 2 were provided by the Neuromuscular tissue bank of the Fondazione Ospedale Maggiore Mangiagalli e Regina Elena and muscle samples of patient 3 and 4 by the Neuromuscular tissue bank of the University of Ljubljana. Both centres are partners of the EuroBioBank network (www.eurobiobank.org). The financial support of Associazione Amici del Centro del Dino Ferrari-University of Milan, the Telethon Network of Genetic Biobanks project no. GTB1200 and the Eurobionank project LLTR-2011-02769 are gratefully acknowledged (SM, MM and FG). MJ, LGE and RPE are funded by the Ministerio de Ciencia e Innovación \& Instituto de Salud Carlos III, Spain (Ref Pl10/00662) and the Departamento de Ciencia, Tecnología y Universidad del Gobierno de Aragón y Fondo Social Europeo (Grupo B33). We are grateful for technical support from the Unitat de Microscòpia Confocal-Campus Diagonal of the Centres Científics i Tecnològics of the Universitat de Barcelona (CCiT-UB). We are grateful for support from the Duchenne Parent Project Spain and the Federación Española de Enfermedades Neuromusculares (ASEM).

\section{Author details}

${ }^{1}$ Bioinformatics Core Facility, IDIBAPS, Hospital Clinic, Barcelona, Spain ${ }^{2}$ Neuromuscular Unit, Neurology Department, Fundación Sant Joan de Déu, Hospital Sant Joan de Déu, Barcelona, Spain. ${ }^{3}$ Pathology Department, Hospital Sant Joan de Déu, Barcelona, Spain. ${ }^{4}$ Institute of Anatomy, Faculty of Medicine, University of Ljubljana, Ljubljana, Slovenia. ${ }^{5}$ Department of Child, Adolescent, and Developmental Neurology, Children's Hospital, University Medical Centre Ljubljana, Ljubljana, Slovenia. ${ }^{6}$ U.O.S. Diagnostica Malattie Neuromuscolari, Fondazione Ospedale Maggiore Mangiagalli e Regina Elena, IRCCS, Milan, Italy. ${ }^{7}$ Laboratory for Neuropathology, Ghent University Hospital, Ghent, Belgium. ${ }^{8}$ Institute of Neuropathology, Hospital de Bellvitge, Barcelona, Spain. ${ }^{9}$ Neuropaediatrics Department, Vall d'Hebron Hospital, Barcelona, Spain. ${ }^{10}$ Biochemistry and Molecular Biology Department, University of Zaragoza, Zaragoza, Spain. ${ }^{11}$ Center for Biomedical Research on Rare Diseases (CIBERER), Instituto de Salud Carlos III, Madrid, Spain. ${ }^{12}$ Clinical Biochemistry Department, Hospital Sant Joan de Déu, Barcelona, Spain. ${ }^{13}$ Orthopaedic Surgery \& Traumatology Department, Hospital Sant Joan de Déu, Barcelona, Spain.
Received: 21 May 2013 Accepted: 28 January 2014

Published: 1 February 2014

\section{References}

1. Uziel G, Ghezzi D, Zeviani M: Infantile mitochondrial encephalopathy. Semin Fetal Neonatal Med 2011, 16(4):205-215.

2. Dimauro S: A history of mitochondrial diseases. J Inherit Metab Dis 2011, 34(2):261-276.

3. DiMauro S: Pathogenesis and treatment of mitochondrial myopathies: recent advances. Acta Myol 2010, 29(2):333-338.

4. Calvo $S$, Jain M, Xie X, Sheth SA, Chang B, Goldberger OA, Spinazzola A, Zeviani M, Carr SA, Mootha VK: Systematic identification of human mitochondrial disease genes through integrative genomics. Nat Genet 2006, 38(5):576-582.

5. Fellman V, Suomalainen A: Mitochondrial disorders in the perinatal period. Semin Fetal Neonatal Med 2011, 16(4):173-174.

6. Zeviani M, Carelli V: Mitochondrial disorders. Curr Opin Neurol 2007, 20(5):564-571

7. Suomalainen A, Isohanni P: Mitochondrial DNA depletion syndromes-many genes, common mechanisms. Neuromuscul Disord 2010, 20(7):429-437.

8. Vila MR, Villarroya J, Garcia-Arumi E, Castellote A, Meseguer A, Hirano M, Roig M: Selective muscle fiber loss and molecular compensation in mitochondrial myopathy due to TK2 deficiency. J Neurol Sci 2008, 267(1-2):137-141.

9. Mancuso M, Salviati L, Sacconi S, Otaegui D, Camano P, Marina A, Bacman S, Moraes CT, Carlo JR, Garcia M, Garcia-Alvarez M, Monzon L, Naini AB, Hirano M, Bonilla E, Taratuto AL, DiMauro S, Vu TH: Mitochondrial DNA depletion: mutations in thymidine kinase gene with myopathy and SMA. Neurology 2002, 59(8):1197-1202.

10. Tulinius $M$, Oldfors A: Neonatal muscular manifestations in mitochondrial disorders. Semin Fetal Neonatal Med 2011, 16(4):229-235.

11. Spinazzola A, Zeviani M: Disorders from perturbations of nuclearmitochondrial intergenomic cross-talk. J Intern Med 2009, 265(2):174-192

12. Galbiati S, Bordoni A, Papadimitriou D, Toscano A, Rodolico C, Katsarou E, Sciacco M, Garufi A, Prelle A, Aguennouz M, Bonsignore M, Crimi M, Martinuzzi A, Bresolin N, Papadimitriou A, Comi GP: New mutations in TK2 gene associated with mitochondrial DNA depletion. Pediatr Neurol 2006, 34(3):177-185

13. Zhou X, Solaroli N, Bjerke M, Stewart JB, Rozell B, Johansson M, Karlsson A Progressive loss of mitochondrial DNA in thymidine kinase 2-deficient mice. Hum Mol Genet 2008, 17(15):2329-2335.

14. Bartesaghi S, Betts-Henderson J, Cain K, Dinsdale D, Zhou X, Karlsson A, Salomoni P, Nicotera P: Loss of thymidine kinase 2 alters neuronal bioenergetics and leads to neurodegeneration. Hum Mol Genet 2010, 19(9):1669-1677.

15. Akman HO, Dorado B, Lopez LC, Garcia-Cazorla A, Vila MR, Tanabe LM, Dauer WT, Bonilla E, Tanji K, Hirano M: Thymidine kinase $2(\mathrm{H} 126 \mathrm{~N})$ knockin mice show the essential role of balanced deoxynucleotide pools for mitochondrial DNA maintenance. Hum Mol Genet 2008, 17(16):2433-2440.

16. Nevo Y, Soffer D, Kutai M, Zelnik N, Saada A, Jossiphov J, Messer G, Shaag A, Shahar E, Harel S, Elpeleg O: Clinical characteristics and muscle pathology in myopathic mitochondrial DNA depletion. J Child Neurol 2002, 17(7):499-504

17. Vila MR, Segovia-Silvestre T, Gamez J, Marina A, Naini AB, Meseguer A, Lombes A, Bonilla E, DiMauro S, Hirano M, Andreu AL: Reversion of mtDNA depletion in a patient with TK2 deficiency. Neurology 2003, 60(7):1203-1205.

18. Ikeda K, Emoto N, Matsuo M, Yokoyama M: Molecular identification and characterization of a novel nuclear protein whose expression is up-regulated in insulin-resistant animals. J Biol Chem 2003, 278(6):3514-3520.

19. Clancy KP, Berger R, Cox M, Bleskan J, Walton KA, Hart I, Patterson D: Localization of the L-glutamine synthetase gene to chromosome 1q23. Genomics 1996, 38(3):418-420.

20. Nabhan JF, Pan H, Lu Q: Arrestin domain-containing protein 3 recruits the NEDD4 E3 ligase to mediate ubiquitination of the beta2-adrenergic receptor. EMBO Rep 2010, 11(8):605-611.

21. Paco S, Ferrer I, Jou C, Cusi V, Corbera J, Torner F, Gualandi F, Sabatelli P, Orozco A, Gomez-Foix AM, Colomer J, Nascimento A, Jimenez-Mallebrera C: Muscle fiber atrophy and regeneration coexist in collagen VI-deficient human muscle: role of calpain-3 and nuclear factor-kappaB signaling. J Neuropathol Exp Neurol 2012, 71(10):894-906. 
22. Dominguez-Rodriguez A, Abreu-Gonzalez P, Avanzas P: Relation of growth-differentiation factor 15 to left ventricular remodeling in STsegment elevation myocardial infarction. Am J Cardiol 2011, 108(7):955-958.

23. Kristiansen M, Menghi $F$, Hughes $R$, Hubank $M$, Ham J: Global analysis of gene expression in NGF-deprived sympathetic neurons identifies molecular pathways associated with cell death. BMC Genomics 2011, 12:551-2164. 12-551.

24. da Huang W, Sherman BT, Lempicki RA: Systematic and integrative analysis of large gene lists using DAVID bioinformatics resources. Nat Protoc 2009, 4(1):44-57.

25. Anderson DD, Quintero CM, Stover PJ: Identification of a de novo thymidylate biosynthesis pathway in mammalian mitochondria. Proc Natl Acad Sci USA 2011, 108(37):15163-15168.

26. Engel K, Hohne W, Haberle J: Mutations and polymorphisms in the human argininosuccinate synthetase (ASS1) gene. Hum Mutat 2009, 30(3):300-307.

27. Puisac B, Ramos M, Arnedo M, Menao S, Gil-Rodriguez MC, Teresa-Rodrigo ME, Pie A, de Karam JC, Wesselink JJ, Gimenez I, Ramos FJ, Casals N, Gomez-Puertas P, Hegardt FG, Pie J: Characterization of splice variants of the genes encoding human mitochondrial HMG-CoA lyase and HMG-CoA synthase, the main enzymes of the ketogenesis pathway. Mol Biol Rep 2012, 39(4):4777-4785.

28. Hulsen T, de Vlieg J, Alkema W: BioVenn - a web application for the comparison and visualization of biological lists using area-proportional Venn diagrams. BMC Genomics 2008, 9:488-2164. 9-488.

29. Zhu CH, Mouly V, Cooper RN, Mamchaoui K, Bigot A, Shay JW, Di Santo JP, Butler-Browne GS, Wright WE: Cellular senescence in human myoblasts is overcome by human telomerase reverse transcriptase and cyclindependent kinase 4: consequences in aging muscle and therapeutic strategies for muscular dystrophies. Aging Cell 2007, 6(4):515-523.

30. Roth $\mathrm{P}$, Junker $\mathrm{M}$, Tritschler I, Mittelbronn M, Dombrowski $Y$, Breit SN, Tabatabai G, Wick W, Weller M, Wischhusen J: GDF-15 contributes to proliferation and immune escape of malignant gliomas. Clin Cancer Res 2010, 16(15):3851-3859.

31. de Mast Q, Syafruddin D, Keijmel S, Riekerink TO, Deky O, Asih PB, Swinkels DW van der Ven AJ: Increased serum hepcidin and alterations in blood iron parameters associated with asymptomatic $P$. falciparum and $P$. vivax malaria. Haematologica 2010, 95(7):1068-1074.

32. Crimi M, Bordoni A, Menozzi G, Riva L, Fortunato F, Galbiati S, Del Bo R, Pozzoli U, Bresolin N, Comi GP: Skeletal muscle gene expression profiling in mitochondrial disorders. FASEB J 2005, 19(7):866-868.

33. Villarroya J, de Bolos C, Meseguer A, Hirano M, Vila MR: Altered gene transcription profiles in fibroblasts harboring either TK2 or DGUOK mutations indicate compensatory mechanisms. Exp Cell Res 2009, 315(8):1429-1438.

34. Tyynismaa H, Carroll CJ, Raimundo N, Ahola-Erkkila S, Wenz T, Ruhanen H, Guse K, Hemminki A, Peltola-Mjosund KE, Tulkki V, Oresic M, Moraes CT, Pietilainen K, Hovatta I, Suomalainen A: Mitochondrial myopathy induces a starvation-like response. Hum Mol Genet 2010, 19(20):3948-3958.

35. Kilberg MS, Pan YX, Chen H, Leung-Pineda V: Nutritional control of gene expression: how mammalian cells respond to amino acid limitation. Annu Rev Nutr 2005, 25:59-85.

36. MacFarlane AJ, Anderson DD, Flodby P, Perry CA, Allen RH, Stabler SP, Stover PJ: Nuclear localization of de novo thymidylate biosynthesis pathway is required to prevent uracil accumulation in DNA. $J$ Biol Chem 2011, 286(51):44015-44022

37. Owusu-Ansah E, Yavari A, Mandal S, Banerjee U: Distinct mitochondrial retrograde signals control the G1-S cell cycle checkpoint. Nat Genet 2008, 40(3):356-361

38. Lane $D$, Levine A: 553 Research: the past thirty years and the next thirty years. Cold Spring Harb Perspect Biol 2010, 2(12):a000893.

39. Vadrot N, Ghanem S, Braut F, Gavrilescu L, Pilard N, Mansouri A, Moreau R, Reyl-Desmars F: Mitochondrial DNA maintenance is regulated in human hepatoma cells by glycogen synthase kinase 3beta and p53 in response to tumor necrosis factor alpha. PLoS One 2012, 7(7):e40879.

40. Kotsinas A, Aggarwal V, Tan EJ, Levy B, Gorgoulis VG: PIG3: a novel link between oxidative stress and DNA damage response in cancer. Cancer Lett 2012, 327(1-2):97-102.

41. Zhang J, Chen X: Posttranscriptional regulation of p53 and its targets by RNA-binding proteins. Curr Mol Med 2008, 8(8):845-849.
42. Lebedeva MA, Eaton JS, Shadel GS: Loss of p53 causes mitochondrial DNA depletion and altered mitochondrial reactive oxygen species homeostasis. Biochim Biophys Acta 2009, 1787(5):328-334.

43. Kimura T, Takeda S, Sagiya Y, Gotoh M, Nakamura Y, Arakawa H: Impaired function of p53R2 in Rrm2b-null mice causes severe renal failure through attenuation of dNTP pools. Nat Genet 2003, 34(4):440-445.

44. Merlini L, Angelin A, Tiepolo T, Braghetta P, Sabatelli P, Zamparelli A, Ferlini A, Maraldi NM, Bonaldo P, Bernardi P: Cyclosporin A corrects mitochondrial dysfunction and muscle apoptosis in patients with collagen VI myopathies. Proc Natl Acad Sci USA 2008, 105(13):5225-5229.

45. Aure K, Fayet G, Leroy JP, Lacene E, Romero NB, Lombes A: Apoptosis in mitochondrial myopathies is linked to mitochondrial proliferation. Brain 2006, 129(Pt 5):1249-1259.

46. Collins J, Bonnemann CG: Congenital muscular dystrophies: toward molecular therapeutic interventions. Curr Neurol Neurosci Rep 2010, 10(2):83-91.

47. Maddocks OD, Vousden KH: Metabolic regulation by p53. J Mol Med (Berl) 2011, 89(3):237-245.

48. Strelau J, Bottner M, Lingor P, Suter-Crazzolara C, Galter D, Jaszai J, Sullivan A, Schober A, Krieglstein K, Unsicker K: GDF-15/MIC-1 a novel member of the TGF-beta superfamily. J Neural Transm Supp/ 2000(60):273-276. Review.

49. Tong S, Ngian GL, Onwude JL, Permezel M, Saglam B, Hay S, Konje JC, Marczylo TH, Fleming G, Walker SP, Lappas M: Diagnostic accuracy of maternal serum macrophage inhibitory cytokine-1 and pregnancyassociated plasma protein-A at 6-10 weeks of gestation to predict miscarriage. Obstet Gynecol 2012, 119(5):1000-1008.

50. Brown DA, Hance KW, Rogers CJ, Sansbury LB, Albert PS, Murphy G, Laiyemo AO, Wang Z, Cross AJ, Schatzkin A, Danta M, Srasuebkul P, Amin J, Law M, Breit SN, Lanza E: Serum macrophage inhibitory cytokine-1 (MIC-1/GDF15): a potential screening tool for the prevention of colon cancer? Cancer Epidemiol Biomarkers Prev 2012, 21(2):337-346.

51. Osada M, Park HL, Park MJ, Liu JW, Wu G, Trink B, Sidransky D: A p53-type response element in the GDF15 promoter confers high specificity for p53 activation. Biochem Biophys Res Commun 2007, 354(4):913-918.

52. Suomalainen A, Elo JM, Pietilainen $K H$, Hakonen AH, Sevastianova K, Korpela M, Isohanni P, Marjavaara SK, Tyni T, Kiuru-Enari S, Pihko H, Darin N, Ounap K, Kluijtmans LA, Paetau A, Buzkova J, Bindoff LA, Annunen-Rasila J, Uusimaa J, Rissanen A, Yki-Jarvinen H, Hirano M, Tulinius M, Smeitink J, Tyynismaa H: FGF-21 as a biomarker for muscle-manifesting mitochondrial respiratory chain deficiencies: a diagnostic study. Lancet Neuro/ 2011, 10(9):806-818.

53. Dubowitz VSC: Muscle Biopsy: A Practical Approach. 3rd edition. London: Saunders Elsevier; 2007.

54. Smyth GK, Speed T: Normalization of cDNA microarray data. Methods 2003, 31(4):265-273

55. Breitling R, Armengaud P, Amtmann A, Herzyk P: Rank products: a simple, yet powerful, new method to detect differentially regulated genes in replicated microarray experiments. FEBS Lett 2004, 573(1-3):83-92.

doi:10.1186/1471-2164-15-9

Cite this article as: Kalko et al:: Transcriptomic profiling of TK2 deficient human skeletal muscle suggests a role for the $p 53$ signalling pathway and identifies growth and differentiation factor-15 as a potential nove biomarker for mitochondrial myopathies. BMC Genomics 2014 15:91.

\section{Submit your next manuscript to BioMed Central and take full advantage of:}

- Convenient online submission

- Thorough peer review

- No space constraints or color figure charges

- Immediate publication on acceptance

- Inclusion in PubMed, CAS, Scopus and Google Scholar

- Research which is freely available for redistribution 